\title{
Fiscal implications of AIDS in South Africa
}

\author{
Lars M. Johansson* \\ Department of Economics, Stockholm University, S-106 91 Stockholm. \\ E-mail: lj@ne.su.se.
}

June 14, 2006

\begin{abstract}
The number of people living with HIV is alarmingly large. In addition to the incomprehensible human suffering of those directly affected, AIDS also has large, negative economic effects. In this paper, I study the fiscal implications of the HIV/AIDS epidemic in South Africa in a standard neo-classical growth model. I find that an antiretroviral program is to a large extent self financing. Improvement in dependency ratios and health care cost savings would pay for Rand 144 billion of a full epidemiological intervention. The indirect effect through the changing demographic structure will be more important than the direct health care cost saving effect. I also explore different taxation policies. The households would be willing to sacrifice an amount equal to $12 \%$ of GDP in the first period to be subject to an optimal (Ramsey) fiscal policy rather than an alternative fixed debt to GDP policy. The optimal policy implies an increase in government debt during the peak of the epidemic.
\end{abstract}

Keywords: AIDS; Fiscal impact; Economic impact; Fiscal policy; Taxation

JEL Classification: E17; E21; E23; E62; H21; H23

*I thank the Centre for Social Science Research at University of Cape Town for letting me use their facilities. I would also like to thank Harry Flam, Matthew Lindquist, Nicolli Natrass, Kjetil Storesletten and two anonymous reviewers for valuable comments and advice. Finally, I would like to thank Finanspolitiska Forskningsinstitutet and the Swedish Development Cooperation Agency for financial support. 


\section{Introduction}

The number of people living with HIV is alarmingly large. The global estimate for the end of 2005 was 38.6 million. Two thirds of those infected with HIV live in SubSaharan Africa. Several countries in this region have adult infection rates exceeding 20\%. In South Africa, about 5 million people currently live with the infection, which is the highest absolute number of HIV + people in any country, although not the highest prevalence rate (UNAIDS, 2006). ${ }^{1}$

AIDS related deaths are dramatically changing the demographic structure of these African countries. In addition to the incomprehensible human suffering of those directly affected, AIDS also has large, negative economic effects on these countries; many of which are already struggling with problems of severe poverty.

This paper explores the economic effects of AIDS in South Africa from 2000 to 2030. This is done in a standard neo-classical growth model where I focus on the fiscal effects of AIDS. The two main questions addressed in this paper are: Can policy interventions designed to treat AIDS patients and fight the spread of AIDS in South Africa be (at least partially) self-financing? What is the optimal government policy of taxes and transfers during a prolonged struggle against AIDS?

South Africa has experienced a long-run demographic transition with falling dependency ratios, due to the fact that most families now have fewer children. However, over the next few years, the dependency ratio will not fall as quickly as it would have in the absence of AIDS. ${ }^{2}$

Figure 1 displays the expected number of new HIV + per age group in South Africa in 2005. The number of new HIV cases peaks at ages 20-25, albeit somewhat

\footnotetext{
${ }^{1}$ The infection rate among the adult population in SA is estimated to be $18.8 \%$ (UNAIDS, 2006).

${ }^{2}$ In this paper, the dependency ratio is defined as young, old and AIDS-sick in relation to the non-AIDS-sick working age population (i.e. 16-65 years of age). Source: based on forecast from the Actuarial Society of South Africa's demographic model. Evidence from other countries points in the same direction. In Botswana, it is estimated that every income earner in the households belonging to the lowest income quartile can expect an additional four dependents as an effect of AIDS (BIDPA, 2000)
} 
earlier for women and somewhat later for men. ${ }^{3}$ Some five to ten years after people have become infected, they will fall ill with AIDS and die, after a shorter or longer time of illness, unless they receive treatment with antiretroviral drugs. Currently, many poor South Africans do not have access to these drugs. AIDS related deaths are expected to peak at ages 30-40.

Figure 1: New HIV infections per age group

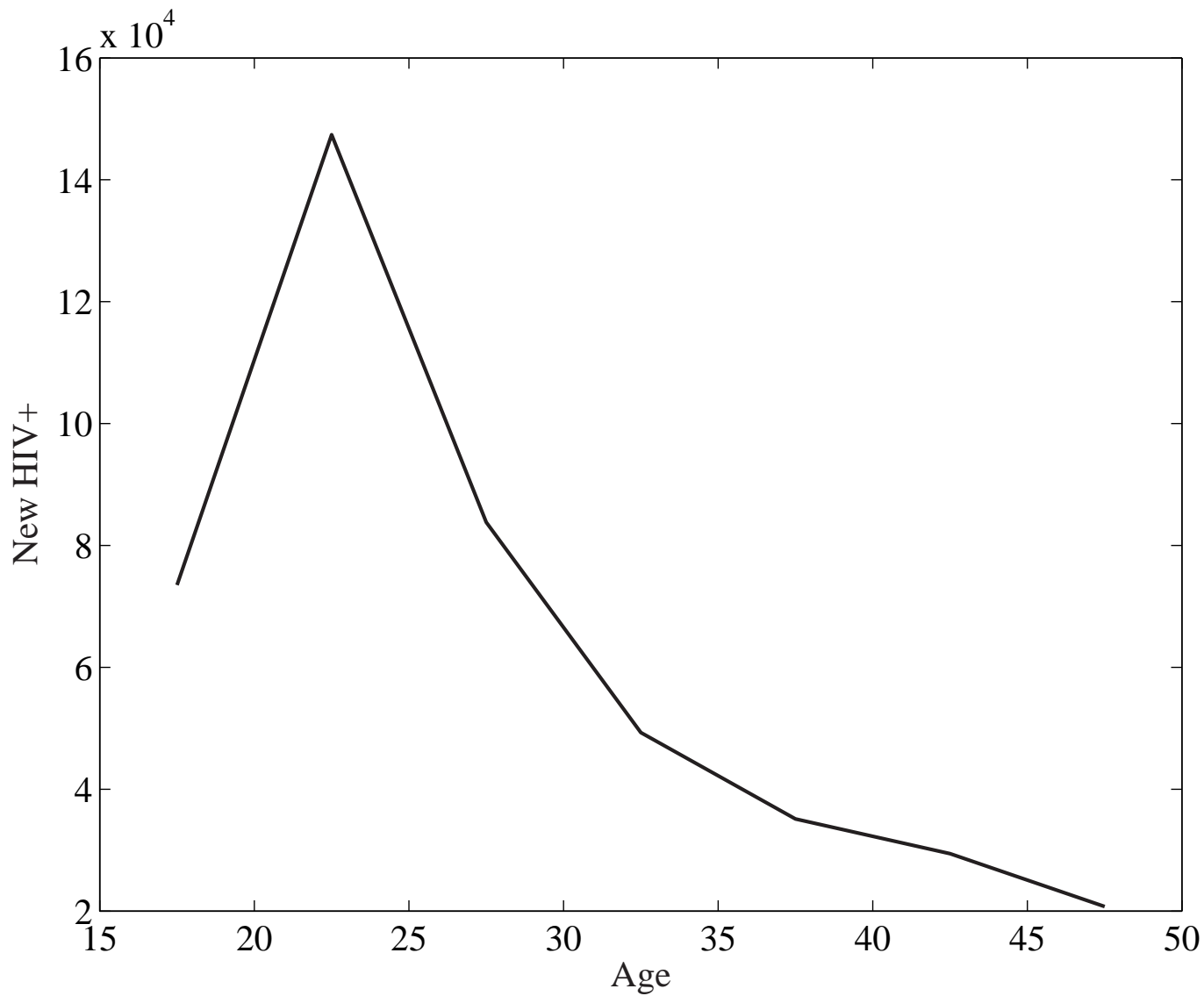

Notes: Based on predictions from the Actuarial Society of South Africa's (ASSA) demographic model for the year 2005 .

This means that the HIV + tend to die at the age when they would otherwise be important contributors to the livelihood of their families. Moreover, in terms of the joint public budget, this group is the major contributor. The net beneficiaries of

\footnotetext{
${ }^{3}$ There are also a number of newborns that get the virus through mother to child transmission. Otherwise, there are basically no new HIV infections among young people until they become sexually active.
} 
Figure 2: Fiscal profile and AIDS deaths
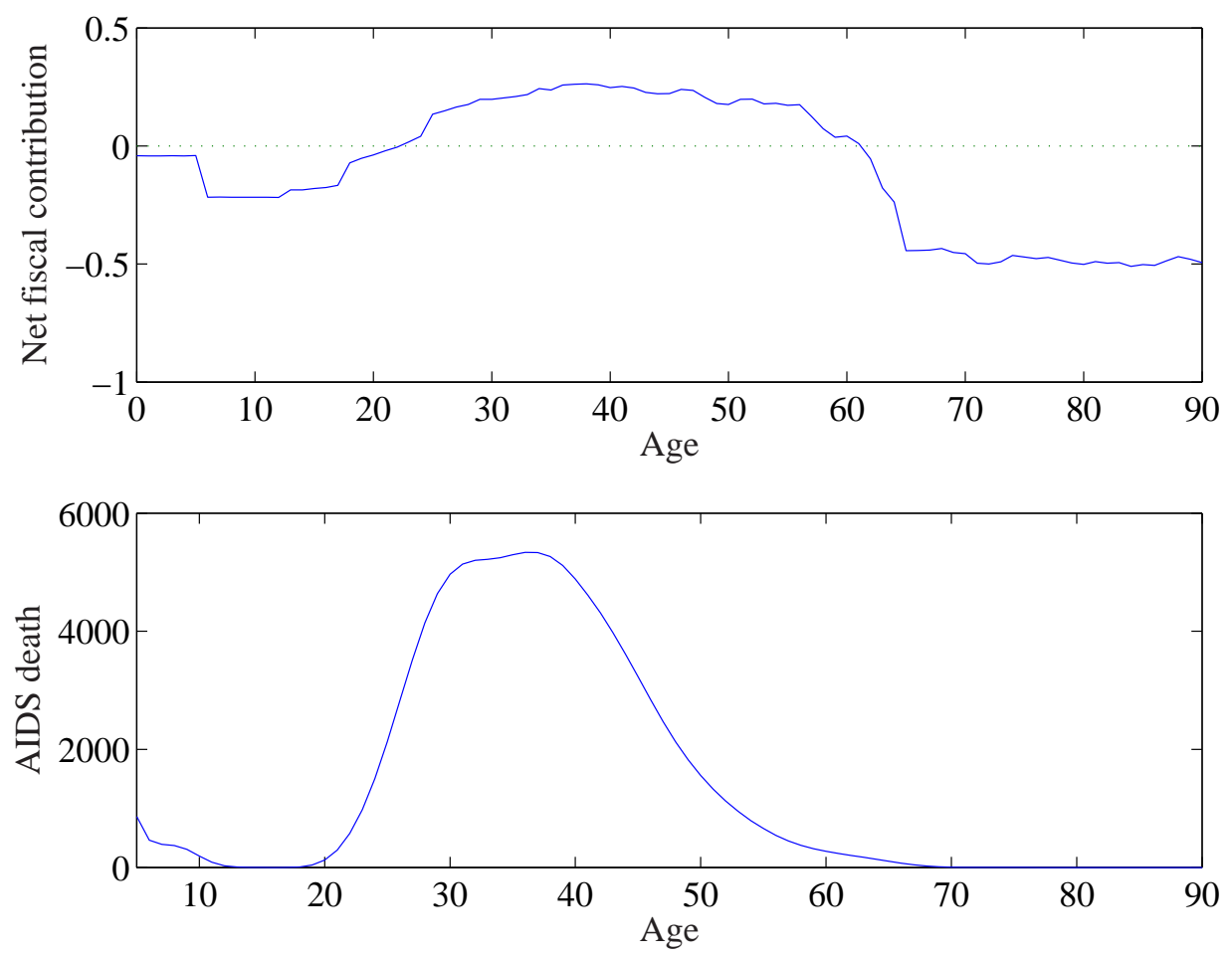

Notes: The AIDS death profile is based on predictions from the ASSA's demographic model for the year 2005. The fiscal profile is a compilation of the tax-, transfer- and public consumptionprofiles used in this paper. See section 3 and appendix B for more details.

government transfers and public goods (i.e. the relatively young and old) are groups not directly hit by AIDS themselves (except for infants that get HIV through mother to child transmission) but their need for support from the government will increase as an effect of the epidemic.

The top graph in figure 2 plots an estimate of the age profile of net fiscal contributions. The bottom graph in figure 2 shows the age profile of AIDS deaths. Mortality rates are at their highest when people would otherwise start to become fiscal net contributors. Clearly, the AIDS epidemic will put a significant strain on the fiscal balance as an increasing number of people become infected. This effect, however, will be somewhat reduced by the lower infection rate among the rich and the fact that wealthy people will most likely have access to antiretroviral drugs. 
The continued development of the epidemic to a large extent depends on government policies. In South Africa, information campaigns reach a large part of the population, while antiretroviral drugs (ARV) only reach a smaller share of those in need. There has been a debate on whether South Africa can afford to implement an ARV-program on a broad scale (Nattrass, 2004). The government response to the need for an ARV-program has been delayed, with reference to the high costs. So, even if it is believed that the motivation for AIDS-intervention should be based on humanitarian reasoning, it must still be a good idea to look at the fiscal benefits of AIDS intervention programs. Can these benefits offset the direct costs of an intervention?

In this paper, I study the fiscal effects of AIDS and search for an optimal taxation policy in a standard neo-classical growth model, similar to that used in Flodén (2003). I use demographic forecasts by South African demographic experts. These forecasts are based on different assumptions with regard to the level of epidemiological intervention chosen by the South African government. I first analyze how different epidemiological interventions affecting the demographic structure will influence the flows of taxes, transfers and government consumption. Together, these flows can be used to quantify the fiscal impact of the interventions. Then, I calculate how taxes and debt should be allocated over the epidemic cycle if the government wants to maximize household welfare. I also estimate the size of the welfare effect of choosing a suboptimal policy. A fixed debt policy represents the suboptimal policy (i.e. a policy resembling the current conservative fiscal policy by the South African government).

The assumption made about the household's credit constraint is critical for the result. In many macro papers on AIDS, some exogenously fixed savings rate is applied which is equivalent to setting a rather tight credit constraint. The baseline in this model is also a tight credit constraint (but I also explore the implication of loosening this constraint and allow for free intertemporal reallocation of consumption). 
During the last few years, there have been a number of macro-studies on the impact of AIDS in South Africa. The first ones took a short to medium term perspective (Arndt and Lewis, 2000; ING Barings Southern Africa ltd., 2000; BER, 2001). The aim of these studies has been to quantify the effects of AIDS on GDP growth and other macro-economic indicators. All three studies find a negative impact of AIDS on GDP growth as compared to a no AIDS scenario.

The first study was conducted by ING Barings Southern Africa ltd. (2000). Their model can be described as a full, supply-demand econometric model and includes a large number of behavioral and technological equations. The second study was carried out by the Bureau of Economic Research at University of Stellenbosch (BER, 2001). They identified a number of channels through which AIDS might have an impact on the South African economy and performed a macro-econometric simulation exercise to assess the effects of the AIDS epidemic. The third study (Arndt and Lewis, 2000) used a neoclassical computable general equilibrium model. Their model can be described as a series of static equilibriums joined together by a set of updating rules and they found a negative impact of AIDS on GDP per capita. The other studies found negative growth effects, but not in per capita terms.

All these modeling strategies allow the researcher to include a large degree of sector and goods heterogeneity. But they are not dynamic in the sense of the decision of the agents being the result of constrained intertemporal optimization.

The model in this paper is a truly dynamic model with intertemporal optimization by households and firms, as well as by the government. However, I do not attempt to estimate the long-run growth effects which has been done by Bell et al. (2003) and Young (2005). In their respective study, they endogenise the impact of AIDS on human capital and productivity. Interestingly, they arrive at opposite conclusions regarding the long-run economic impact of the AIDS epidemic. According to Young, the positive effect of lower population growth will be enough to counteract the negative impact on human capital of AIDS-orphaned children. The basic mechanism leading to this result is the epidemiologically induced increase in the 
capital-labor ratio.

Bell et. al., on the other hand, are more pessimistic about the economic impact of AIDS. For South Africa, they conclude that: "As things now stand, the economy could be on the brink of a progressive collapse". In Bell et. al.'s paper, there is a mechanism for intergenerational accumulation of human capital that is adversely affected by AIDS. Low expected utility from education will lead to less investment in education and may eventually lead to a poverty trap with no, or minimum, investment in education. In Young, education is an optimal consumption decision by the parents. However, there is not the same kind of accumulation of human capital over time; hence, AIDS will not have the same long-run detrimental effect as in Bell et al. In Young's setting, AIDS will lead to reduced labor supply, increasing wages and larger income to survivors.

The focus of this paper is rather on the fiscal impact of AIDS over the medium time perspective (i.e. 30 years). In this time frame, AIDS may very well have an impact on human capital, but it is as yet difficult to say what it will be. There is some evidence that the effect is not that large after all. ${ }^{4}$ Therefore, I abstract from any impact of AIDS on human capital formation. Since the focus is on the medium-term perspective, it makes more sense to treat the population dynamics as exogenous to the model and hence, accept the forecasts made by the South African Actuarial Society's model under different epidemiological assumptions. Given these forecasts, I look at the fiscal and welfare impact of different fiscal policies assessing the importance of tax regimes - an optimal Ramsey policy vs. a fixed debt policy.

I also assess the importance of the household credit constraint. Many macro models of AIDS do assume some sort of credit constraint, for example assuming that all income is consumed within each period or imposing some exogenously fixed savings rate. In this paper, I explore the importance of the credit constraint over the

\footnotetext{
${ }^{4}$ In South Africa, during the 1990s and the early part of the new century, the school enrolment rates for the youngest have not declined while for older teenagers they have declined by 5 percent (from Young (2005), basing his conclusion on information from the October Household Surveys and population censuses).
} 
epidemic cycle by comparing a situation with a completely credit constrained household with that of a household that is free to make any intertemporal reallocation of consumption.

In this study, I find that a welfare optimizing government should reduce the tax rate during the peak of the epidemic and allow the government debt to increase. The value (in terms of the household's willingness to pay) of doing this intertemporal reallocation is equal to around $10 \%$ of GDP in the base year (2000). Furthermore, I also find that a full ARV epidemiological intervention will have a positive fiscal effect that can pay for a large share of the cost of such an intervention. The positive fiscal impact of an intervention is partly due to improvements in dependency ratios and partly to direct cost savings of fewer people needing health care. The lower dependency ratio, however, is more important for the government budget than health care savings.

\section{The model}

I use the model of a small open economy. It is a dynamic model similar to that of Flodén (2003), although in this version, world factor prices are taken as given and I do not model the global economy. Capital can move freely but labor is immobile. The model includes a representative household, a representative firm and a government. The household chooses consumption and labor supply. The government chooses a consumption tax, which is used to finance an exogenously determined expenditure program. The firm determines investment and hiring.

\subsection{The household}

The household chooses consumption (per efficiency unit) and labor supply to maximize utility

$$
\sum_{t=0}^{\infty} \beta^{t} n_{t} U\left(v_{t} \hat{c}_{t}^{a}, v_{t} \hat{c}_{t}^{i}, h_{t}, \alpha_{t}\right),
$$


where $\hat{c}_{t}^{a}$ and $\hat{c}_{t}^{i}$ are consumption per efficiency unit per active and inactive household member in period $t$, respectively. Disregarding the subindex for the moment, $v$ is efficiency units and $h$ is labor supply per active household member. For any variable $x, \hat{x}=x / v$. A share $\alpha$ of the household members is active and $n$ is the size of the household. The household faces an intertemporal budget constraint

$$
a_{t+1}=a_{t}\left(1+r_{t}\right)+n_{t} v_{t}\left(\alpha_{t}\left(1-\tau_{i}\right) w_{t} h_{t}+\hat{s}_{t}-\left(1+\tau_{c, t}\right)\left(\alpha_{t} \hat{c}_{t}^{a}+\left(1-\alpha_{t}\right) \hat{c}_{t}^{i}\right)\right),
$$

where $a$ is household assets, $r$ is the interest rate, $w$ is the wage per efficiency unit, $s$ is transfers, $\tau_{c}$ is the consumption tax and $\tau_{i}$ is the income tax. Assuming a small open economy means that $r_{t}=r_{W}$ for all $t$, where $r_{W}$ is the world market interest rate, assumed to be constant over time. All other variables may change over time.

From the first-order conditions, we get the condition for allocation between consumption and labor

$$
\frac{U_{\hat{c}_{t}^{a}}}{\left(1+\tau_{c, t}\right)}=-\frac{U_{h_{t}}}{\left(1-\tau_{i}\right) w_{t}}
$$

and the relation between consumption for active and inactive individuals

$$
\frac{U_{\hat{c}_{t}^{a}}}{\alpha_{t}}=\frac{U_{\hat{c}_{t}^{i}}}{1-\alpha_{t}}
$$

The Euler equation is

$$
\frac{U_{h_{t}}}{\alpha_{t} v_{t}}=-(1+r) \beta \frac{U_{h_{t+1}}}{\alpha_{t+1} v_{t+1}} .
$$

In the baseline model, I assume that the household faces a total credit constraint and is not able to borrow or save from one period to the next. The constraint is then the same as above but with $a_{t}=0$ for all $t$ and there will not be any Euler-condition to consider. 


\subsection{The firm}

There is a representative firm that behaves competitively. The production function is

$$
y_{t}=A k_{t}^{\theta} H_{t}^{1-\theta}
$$

where $H_{t}=n_{t} \alpha_{t} v_{t} h_{t}$. The price of output is normalized to 1 and the profit is

$$
\pi_{t}=y_{t}-w_{t} H_{t}-\left(\left(1+\tau_{\pi}\right) r_{t}+\delta\right) k_{t}
$$

where $\tau^{\pi}$ is capital income tax and $\delta$ is the depreciation rate. In the closed economy, factor prices are

$$
r_{t}=\frac{\theta y_{t} k_{t}^{-1}-\delta}{\left(1+\tau^{\pi}\right)}
$$

and

$$
w_{t}=(1-\theta) y_{t} H_{t}^{-1}
$$

In the open economy, the interest rate, $r$, is given and hence, also the wage per efficiency unit, $w$, will be given.

$$
w=A(1-\theta) \phi^{\theta}
$$

where

$$
\phi=\left(\frac{\left(\left(1+\tau^{\pi}\right) r_{W}+\delta\right)}{A \theta}\right)^{\frac{1}{\theta-1}}
$$

and then capital, $k$, and output, $y$, will simply be a linear function of the amount of labor, $H$, used, so that

$$
k_{t}=\phi H_{t}
$$

and 


$$
y_{t}=A \phi^{\theta} H_{t} .
$$

\subsection{The Government}

The government collects taxes on wage income, capital income and consumption $\left(\tau_{i}\right.$, $\tau_{\pi}$ and $\tau_{c}$, respectively). It disburses transfers, $s$, and pays for public consumption, $g$. Transfers and public consumption may vary over time but are exogenously determined. $\tau_{i}$ and $\tau_{\pi}$ are also exogenously determined while $\tau_{c}$ is the government's only choice parameter. The government budget constraint is

$$
\begin{gathered}
D_{t+1}=D_{t}\left(1+r_{r}\right)-\tau_{\pi} r_{t} k_{t} \\
+n_{t}\left(g_{t}+s_{t}-\alpha_{t} \tau_{i} w_{t} v_{t} h_{t}-\tau_{c, t}\left(c_{t}^{a}+c_{t}^{i}\right)\right) .
\end{gathered}
$$

In this paper, I consider two different policy objectives: an optimal social policy and a constant debt policy.

\subsubsection{Optimal policy}

Optimal tax policy is derived by optimizing the sum of the household's discounted utility (i.e. eq. 2.1) s.t. the government's budget constraint, the household's budget constraint and first-order condition. I use the primary approach to find the Ramsey allocation, ${ }^{5}$ that is, I will set up the government's problem in terms of allocations and, after having solved for the optimal allocations, the optimal tax rate is derived.

For this purpose, the consumption tax rate needs to be expressed in terms of allocations. Rewriting 2.3, I get

$$
1+\tau_{c, t}=-\frac{U_{\hat{c}_{t}^{a}}\left(1-\tau_{i}\right) w}{U_{h_{t}}} .
$$

\footnotetext{
${ }^{5}$ See Atkinson and Stiglitz, ch. 12 (1980).
} 
This expression for the tax rates is then substituted into the budget constraint for the household to give us the following implementability constraint

$$
\begin{gathered}
a_{t+1}=a_{t}\left(1+r_{t}\right) \\
+n_{t} v_{t}\left(\left(1-\tau_{i}\right) w_{t}\left(\alpha_{t} h_{t}+\frac{U_{\hat{c}_{t}^{a}}}{U_{h_{t}}}\left(\alpha_{t} \hat{c}_{t}^{a}+\left(1-\alpha_{t}\right) \hat{c}_{t}^{i}\right)\right)+\hat{s}_{t}\right) .
\end{gathered}
$$

I substitute the household constraints (eq. 2.2) and the expression for $k$ (eq. 2.12) into the government budget constraint (eq. 2.14) to get

$$
\begin{gathered}
D_{t+1}-a_{t+t}=\left(D_{t}-a_{t}\right)\left(1+r_{t}\right) \\
+v_{t} n_{t}\left[\hat{g}_{t}+\alpha_{t} \hat{c}_{t}^{a}+\left(1-\alpha_{t}\right) \hat{c}_{t}^{i}-\alpha_{t}\left(w_{t}+\tau_{\pi} r \phi\right) h_{t}\right] .
\end{gathered}
$$

The problem for the government is then to maximize household utility (eq. 2.1), subject to the government and the household budget constraints (eq. 2.17 and 2.16) and the Euler conditions for the household (eq. 2.5). Once more, we do not have to consider the Euler condition in the case of a completely credit constrained household.

This is a problem in terms of allocations and exogenously determined parameters only. When the Ramsey allocation is found, the optimal tax schedule can be obtained from eq. 2.15. In steady state $\hat{c}^{a}, \hat{c}^{i}, h, \hat{k}$ and $\hat{y}$ will be constant while $v$ will grow at a steady-state growth rate. ${ }^{6}$

\section{Parameterization}

The utility function is

\footnotetext{
${ }^{6}$ This is sufficient to find a solution to the Ramsey allocation in the open economy. To find the Ramsey allocation in the closed economy, we would also have to use equations 2.8 and 2.9 to substitute for $r$ and $w$ in 2.5. 2.16 and 2.17. However, that is not used in this paper.
} 


$$
\begin{gathered}
U\left(c_{t}^{a}, c_{t}^{i}, h_{t}\right)=\alpha_{t} \frac{\left(c_{t}^{a}\right)^{1-\sigma}}{1-\sigma} \exp \left(-\zeta(1-\sigma)\left(h_{t}^{a}\right)^{1+1 / \gamma}\right)+ \\
\left(1-\alpha_{t}\right) \frac{\left(c_{t}^{i}\right)^{1-\sigma}}{1-\sigma}
\end{gathered}
$$

Risk aversion, $\sigma$, typically ranges between 1 and 3 in the empirical consumption literature. Therefore, I set $\sigma$ to 2. Most estimates for the intertemporal labor-supply elasticity range between 0 and 0.5 for men. However, for women the estimates are higher and Domeij and Floden 2004 argue that empirical estimates generally have a downward bias owing to a failure to consider credit constraints. Therefore, I choose $\gamma=0.7$ which will give an intertemporal labor-supply elasticity close to 0.5 . The preference for leisure $\zeta$ is typically set so that it will give a labor supply that is approximately $1 / 3$ of the available time in developed economies with close to full employment. With the low level of formal employment in South Africa, $\zeta$ is set to give a labor supply that is $1 / 5$ in the first period. The chosen form of the utility function will allow us to include growth in the model. In steady state, we must have $\beta(1-r)=(1+\varpi)^{\sigma}$, where the steady state growth rate $\varpi=0.005$ and interest rate $r=0.02$. Hence, $\beta=0.99$.

I parameterize the model with data mainly from the year 2000. It is assumed that SA at this date is an economy in transition, implementing a policy with a tight budget discipline (here formalized as a fixed debt to GDP ratio). Initial government debt is R 397 billion (or $41 \%$ of GDP, see parameter $D_{0}$ ); that is, the total loan debt net for the government 2001 (source Department of Finance SA, "Budget Review 2003"). Households are assumed to have zero wealth in the initial steady state. Profiles on transfers and public consumption are compiled from data obtained from Statistics South Africa and Government Ministries and work by van der Berg (2001a,b). These profiles are then adjusted so that aggregate transfers and public consumption match those found in macro data in the base year.

In the baseline case, I assume that only a small share of those in need of health 
care because of HIV/AIDS will actually receive it. According to the Department of Health R, 3.6 billion were spent on in- and out-patient hospitalization needs, while Geffen et al. (2003) estimate that the actual need would be R 13.6 billion. Hence, my assumption is that only a share equal to 3.6/13.6 (or 26\%) of AIDS-care need will be meet over the whole epidemic cycle. When compiling the cost of HIV positive patients, I use Geffen et al.'s cost estimates for different stages of the disease.

The income tax and profit tax are set so that the relative tax revenue in the model corresponds to the relative importance of these taxes in public finances. The income tax accounts for $44.24 \%$ of the total tax revenues from income, profits and goods which gives $\tau^{i}=0.14$. In the model, I will use a capital tax instead of a profit tax. The share of the profit tax revenue is $14.80 \%$ which gives $\tau^{\pi}=0.72$. The depreciation rate of capital is set to 0.1 .

Population figures are output from the Actuarial Society of South Africa's model ASSA2003 (henceforth the ASSA model). ${ }^{7}$ The ASSA model forecasts the population of SA by population group disaggregated on age and gender. It includes information on the number of people in various stages of HIV/AIDS under different assumptions on epidemiological interventions. The changing demographic structure is reflected in $n, \alpha$ and $v$. The parameters values chosen, based on information from data or otherwise, are summarized in table 1.

The starting year of the ASSA model is 1985. This is also the starting year of the AIDS epidemic in the ASSA model. With available empirical information, ASSA have parameterized the model for it to reproduce the demographic and epidemiological development in South Africa. In my paper, the year 2000 is the base year and hence, I will use population output from the ASSA model from the year 2000 and onward until 2055. However, in the presentation of the fiscal impact in the next section, I will focus on what happens in the first 30 years.

The model includes a number of epidemiological interventions; an information and education campaign, voluntary counseling and testing and syndromic manage-

\footnotetext{
${ }^{7}$ The model was downloaded on January 2, 2006 from http://www.assa.org.za
} 
Table 1: Parameter values

\begin{tabular}{lcc}
\hline Risk aversion & $\sigma$ & 2 \\
Labor supply parameter & $\gamma$ & 0.7 \\
Preference for leisure & $\zeta$ & $29^{*}$ \\
Discount factor & $\beta$ & 0.99 \\
Interest rate & $r_{W}$ & 0.02 \\
Steady state growth & $\varpi$ & 0.005 \\
Capital's share of income & $\theta$ & 0.3 \\
Total factor productivity & $A$ & $3.47^{*}$ \\
Depreciation of capital & $\delta$ & 0.1 \\
Profit tax & $\tau_{\pi}$ & 0.72 \\
Income tax & $\tau_{i}$ & 0.14 \\
Households' initial assets & $a_{0}$ & 0 \\
Initial Gov. debt/GDP ratio & $D_{0}$ & 0.42 \\
Share of active & $\alpha_{t}$ & $* *$ \\
Productivity units & $v_{t}$ & $* *$ \\
Household size & $n_{t}$ & $* *$ \\
Transfers & $s_{t}$ & $* *$ \\
Government consumption & $g_{t}$ & $* *$ \\
\hline Notes: & & \\
$n_{0}, v_{0}$ and $y_{0}$ are all normalized to one. & \\
$*$ Values determined through calibration. & \\
$* *$ For values, see main text and appendix. &
\end{tabular}


ment of sexually transmitted diseases. These interventions are assumed to have come a long way towards full implementation when this model starts in 2000 and by 2004 , they have reached their long-run coverage levels. The baseline population profile of this paper includes these interventions only.

In addition to these interventions, there are also the mother to child transmission prevention program (MTCTP) and antiretroviral therapy (ARV). These are under introduction and it is difficult to say to what extent the South African population will actually get access to these interventions. The years of introduction of these interventions in the ASSA model are 2000 for ARV and 2001 for MTCTP. In section 4.2, I will explore the fiscal implications of introducing these additional interventions.

I will investigate the fiscal implications of the following three scenarios: first, the above-described scenario with baseline interventions, henceforth referred to as the baseline scenario; second, a scenario including the baseline intervention plus the MTCTP intervention, henceforth referred to as the MTCTP scenario and; finally, a scenario including all interventions in the MTCTP scenario plus the ARV intervention, to which I will refer as the ARV or full intervention scenario.

It is assumed that $45 \%$ of the AIDS sick will not be able to work. ${ }^{8} 25 \%$ of those receiving ART (or having discontinued an ART treatment) are assumed to be AIDS sick. ${ }^{9}$

\section{Results}

In the following, I will use the model presented in section 2 to explore fiscal effects of different policy options in terms of epidemiological interventions (section 4.2). Next, I look at the importance of taxation policy and also explore to what extent this result depends on assumptions about the household's credit constraint (section 4.3). In section 4.4, the implications of the openness of the economy are explored.

\footnotetext{
${ }^{8}$ This is in line with the assumptions made by Arndt and Lewis (2000) and BER (2001), assuming a 50 and 40 percent productivity reduction, respectively.

${ }^{9}$ See appendix B for more details on parameterization.
} 
Note that, in the estimations that follow, I have not included any cost for different epidemiological interventions. The cost for ARV has been falling and it is difficult to know what the future cost will be. Hence, what I will calculate is the fiscal impact net of the cost for interventions, which will indicate how many resources the interventions will liberate, which could be used to partially finance these interventions. In section 5, I will provide some "back of the envelope" calculation on the scope for self-financing of an ARV intervention. Let me first outline a baseline case that will be used as a point of reference, however.

\subsection{Baseline case}

In the baseline case, I assume the household to be completely credit constrained. It may seem like a strong assumption and it is true that many households can borrow when hit by AIDS and the economic stress it implies. However, for many poor households, there is a real limit to how much they can borrow to finance consumption. It is often friends and relatives who provide the means to get by. But when whole communities are struck by the epidemic, there is a also a limit to this option, since your friends and relatives will be in as much need of support as you are. Therefore, the assumption of a totally credit constrained household is appropriate in the context, although I explore the implications of relaxing this assumption in section 4.3 .

However, even if the absolute credit constraint assumption somewhat exaggerates the budgetary restrictions facing the household, the representative household assumption works in the other direction. It implies complete risk sharing between all cohorts. When AIDS hits one cohort, all cohorts will help bear the burden by cutting back on consumption.

The government's goal in the baseline case is to balance the budget by means of a debt target - that is, keeping the debt to GDP rate constant. This constitutes a formalization of the fairly tight fiscal policy of the South African government. 
Hence, we are not looking at the Ramsey allocation in the baseline case. However, in section 4.3, I will compare the baseline allocation with the Ramsey allocation and also try to estimate the welfare effect of an optimal policy, instead of the suboptimal policy of debt targeting (henceforth, I will refer to the taxation policy resulting in the Ramsey allocation as the optimal policy).

Let us now look at what this debt targeting policy implies for taxation over the epidemic cycle. The driving force behind what is happening will be the changing dependency ratio. The dependency ratio is here defined as the population aged 0-15 and above 65, plus those of working age (aged 16-65) that are ill with AIDS in relation to the remaining working age population. In figure 3 , we see the dependency ratio in the top graph and below is the consumption tax rate necessary to give a constant debt/GDP ratio.

From the bottom part of figure 3, we see that the necessary increase in the tax is rather distinct over the peak of the epidemic. The reason for this increase is twofold. First, as more and more people become AIDS sick, there will be more health care expenditures for various opportunistic diseases. Second, the whole age structure changes when people die from AIDS. Relatively more people become net beneficiaries from the public system in relation to prime age taxpayers.

After the peak of the epidemic, the dependency ratio will once more start to fall more rapidly and the government can then lower the tax rate and still keep a fixed debt level. Now, household consumption will also increase (note how consumption catches up after 2012 when the epidemic has peaked, see figure $4^{10}$ ).

In addition to the AIDS epidemic, there is also an ongoing demographic transition in SA due to falling birth rates. The AIDS epidemic will cause the dependency ratio to fall at a slower pace at the beginning of the $21^{\text {st }}$ century. ${ }^{11}$ In the baseline scenario, the share of AIDS sick in the population increases up to its peak in $2012 .^{12}$

\footnotetext{
${ }^{10}$ In the figure, consumption is in terms of per efficiency units.

${ }^{11}$ For comparison, the falling dependency ratio in the absence of AIDS is plotted in the top graph of figure 16 in the appendix, along with the dependency ratio of the AIDS-inclusive baseline scenario.

${ }^{12}$ See figure 16 in the appendix.
} 
Figure 3: Dependency ratios and tax rates
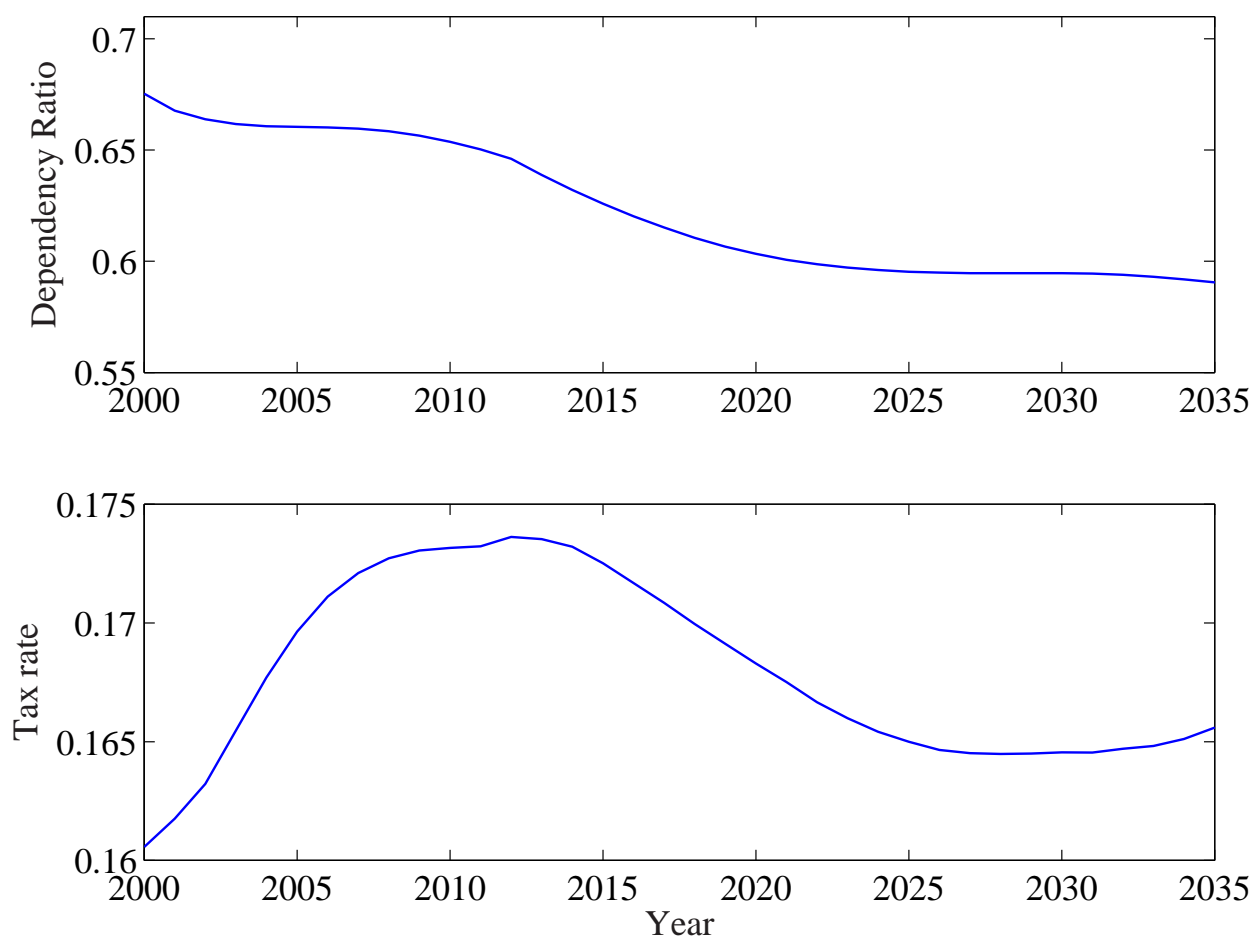

The basic pattern of the dependency ratio in figure 3 is the same, regardless of which epidemiological intervention option the government chooses (see figure 5). But, as we will see below, interventions will still have a significant impact. 
Figure 4: Allocations
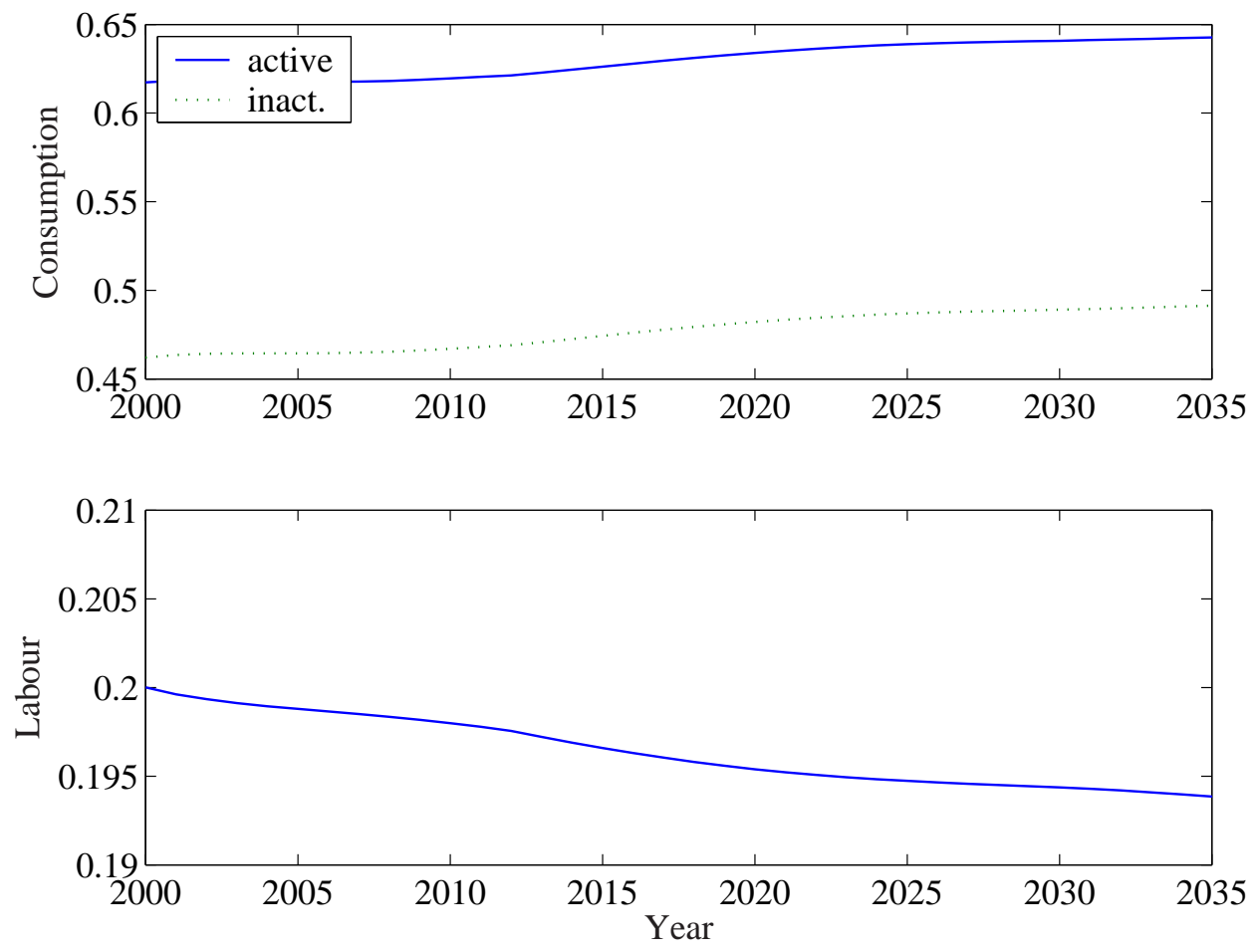

\subsection{The fiscal impact of epidemiological interventions}

In the baseline case, the government does not implement any mother to child transmission prevention (MTCTP) or antiretroviral therapy (ARV). Now, I will allow for the MTCTP and ARV interventions.

We see the dependency ratios for the three different scenarios in figure 5. The differences in dependency ratios are visible four to five years after the interventions have been initiated. An introduction of a full intervention programme including ARV results in lower dependency ratios than in the baseline scenario, due to the reduction in morbidity and death rates among the active population. Only adding an MTCTP intervention without giving people access to ARV will cause the dependency ratio to increase since more children per mother will survive, while there is no reduction in morbidity and death among the active.

Let us assume that the government wants to keep a fixed debt to GDP ratio 
Figure 5: Intervention and dependency ratios

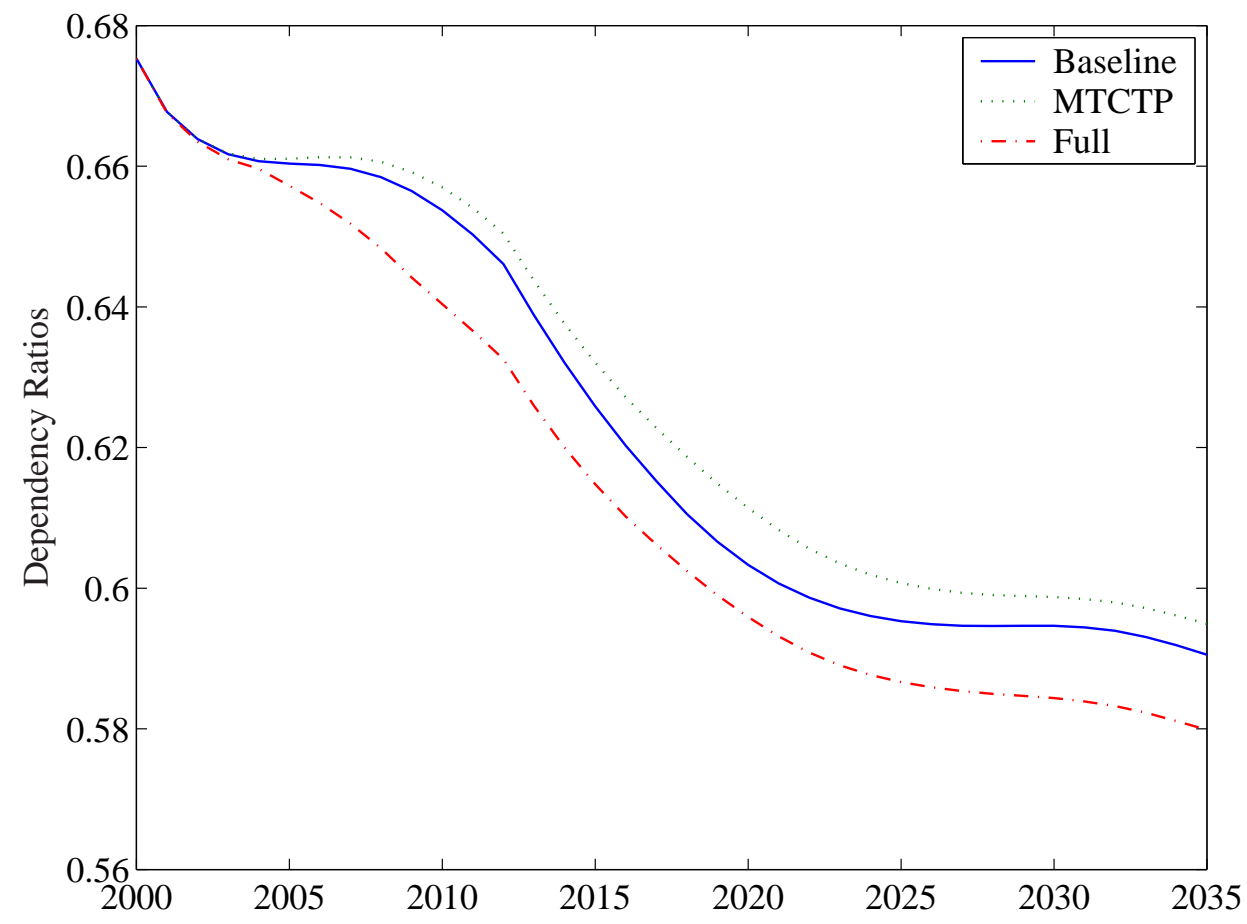

Notes: Based on forecast from the Actuarial Society of South Africa's demographic model.The dependency ratio is defined as young, old and AIDS-sick in relation to the non-AIDS-sick working age population (i.e. 16-65 year of age).

regardless of which intervention policy it pursues. It would then have to use different tax schedules depending on how the population profile changes in the different scenarios. Figure 6 plots tax schedules that would keep the debt ratio constant for the three different interventions. Looking at the year 2015, for example, the tax rate would have to be 1.11 percentage points higher in the no intervention scenario as compared to the full ARV intervention scenario to keep the debt rate constant.

This is one way of comparing the fiscal impact of interventions. Another way is to apply the same tax schedule in all scenarios and instead look at the development of the government debt. This is maybe more interesting, since we can then get an idea of the size of the fiscal benefit of interventions.

Let us use the tax schedule that would give a constant debt to GDP ratio in the baseline scenario and apply it to both the MTCTP- and ARV-scenarios. Figure 7 
Figure 6: Intervention and taxes

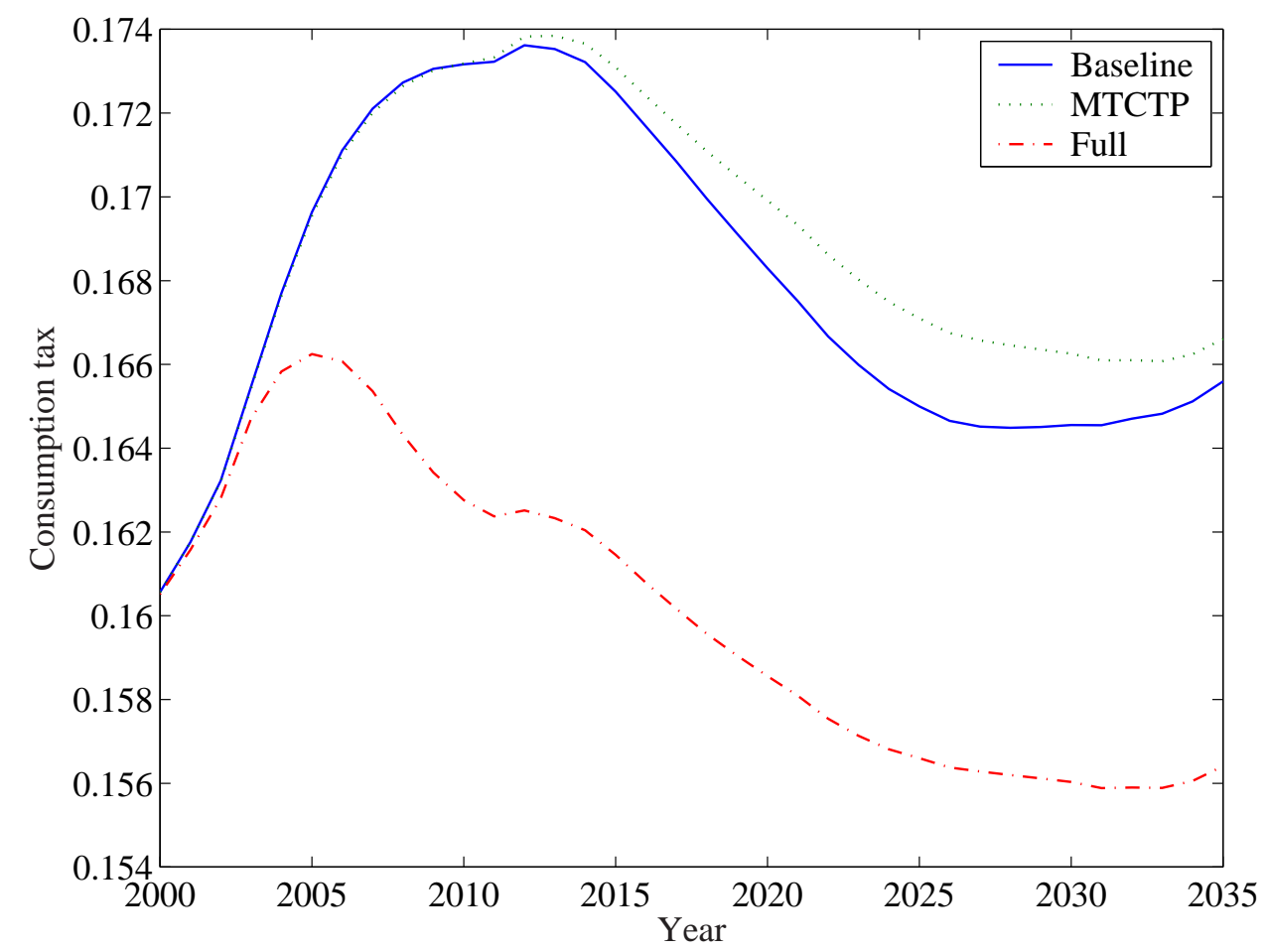

shows the resulting development of government debt in the different cases.

Remember, no cost for the intervention is included in these calculations. Hence, what we are looking at here is the effect on the government budget that comes from the effect of a changing age profile (dependency ratio) of the population, plus the effect of a change in the number of HIV positive people and people with AIDS needing health care.

I can then evaluate the fiscal effect of such an intervention by asking how much additional government debt the government could accept in the first period of the intervention and still be at the same debt to GDP ratio as without the intervention (i.e. given that I keep the same tax rates and spending policies as in the nonintervention case). With full intervention, I can impose an additional debt burden on the government of $10.0 \%$ of GDP in the first period and the debt/GDP ratio would still be the same as in the non-intervention case year 2030. This is, in fiscal 
Figure 7: Intervention and government debt

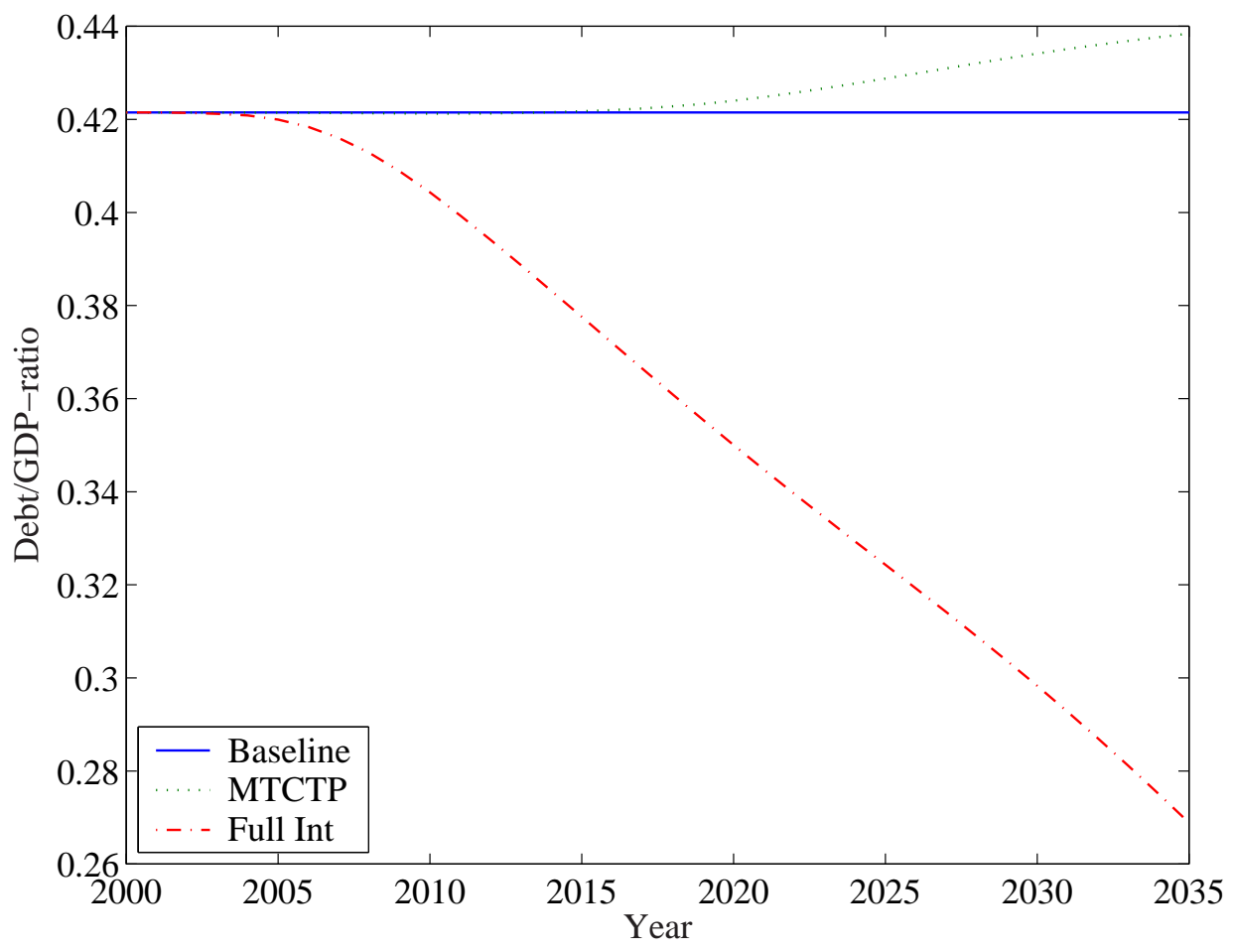

terms, the present value of the intervention, that is how much the government could spend on the intervention until 2030 without losing a Rand. To this extent, the intervention pays for itself (from a narrow fiscal point of view) through the positive demographic effect and health care cost savings. ${ }^{13,14}$

\footnotetext{
${ }^{13}$ If I instead implement all interventions except the ARV intervention, I would then have to make a positive transfer to the government of $1.0 \%$ of GDP, for it not to have a higher debt/GDP ratio in the year 2030. That is, only adding an MTCTP intervention without providing any ARV will give a minor negative fiscal impact.

${ }^{14}$ Adding up the fiscal effects over the period 2000 to 2030 only is a somewhat arbitrary choice. The reason for concentrating on this period is the uncertainty of the demographic development, the further we look into the future. The architects behind ASSA2003 strongly advised against using the model for any further forecast of the population than 25 to 30 years into the future. I do, however, use the ASSA2003 model for a longer forecast used as input in the economic model (see section 3) but when adding up the fiscal effects in this section, I limit the calculation to the period for which the population could be forecasted with some degree of certainty. If I were to choose to ad up the fiscal impact over a shorter period, say 2000 to 2025, the fiscal value of a full ARV intervention (i.e. what the government could spend in present value terms of the interventions during that period and without any effect on government debt) would equal $8.3 \%$ of GDP in the first period. If I were instead to extend the period to 2035 , the fiscal value would equal $11.7 \%$ of GDP.
} 
The fiscal value of the ARV intervention is partly due to the health care cost saving effect of less AIDS related illnesses and partly to the effect of the changing demographic structure on the remaining fiscal flows. The first effect accounts for $1.4 \%$-points of the total effect and the latter effect accounts for the remaining 8.6\%points.

Recall that these estimates are based on the assumption that the current rationing (i.e. 26\% inclusion) of AIDS patients in health care will be constant over the whole evaluated period. With a larger coverage, the potential fiscal benefit of ARV will of course increase. Let us, for example, assume that $60 \%$ of all AIDS patients needing care will get it (though, as before, I am not including treatment). Then, the fiscal benefit of an ARV intervention will increase to 12.7\% in terms of GDP in the first period. ${ }^{15,16}$

The indirect fiscal impact through the demographic structure is rather more important than the direct health care cost saving effect. Still, the direct cost saving effect in the health sector is substantial, the more so the less patient rationing there is. ${ }^{17}$

\subsection{Tax policies}

Tax policies determine which cohorts will carry the burden of the epidemic. In the baseline case, the assumption is that the government wants to keep the debt to GDP ratio constant. Alternatively, I could assume that the government wishes to spread taxation over time in a way that would maximize the discounted sum of household welfare rather than keeping the debt rate constant. Given that the government only implements the baseline intervention, I get the alternative tax schedule shown in figure 8 and the resulting allocations in figure 9 for the fixed debt and optimal tax

\footnotetext{
${ }^{15}$ Now, the health care cost saving effect accounts for $5.2 \%$ and the demographic effect for $7.6 \%$.

${ }^{16}$ The calculations are made in the same way as in the previous example. That is, I find the tax schedule that will give a constant debt in the non-intervention case and then also apply this in the full ARV-intervention case. Thereafter, I evaluate the present value difference in the government debt year 2030 .

${ }^{17}$ This is also demonstrated by the calculation by Geffen et al. (2003).
} 
policy, respectively. ${ }^{18}$ The higher tax for the fixed debt policy has a direct impact on the household in the form of lower consumption. However, the supply of labor is only marginally affected by the choice of policy.

Figure 8: Tax policies and tax rates

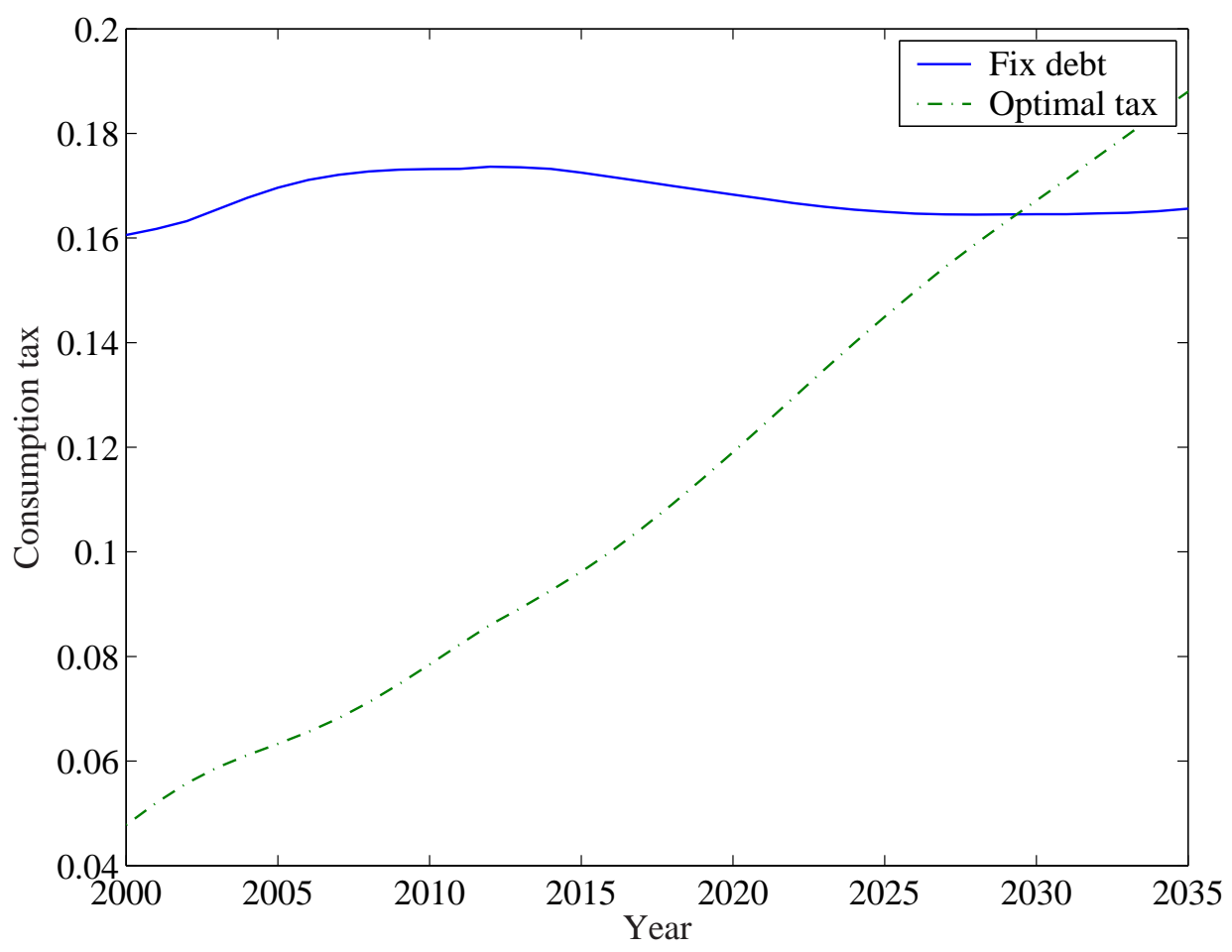

From a welfare point of view, it would be optimal to keep taxation relatively low when the dependency ratio is high. This implies that government debt will build up under this period and future generations will help carry the burden of AIDS through debt servicing. In figure 10, we see how government debt develops under the optimal taxation policy and under the fixed debt/GDP-ratio policy which, by definition, is a straight line.

How can we translate the welfare effect of different taxation policies into some fiscal measure? This can be done by calculating how much we would have to com-

\footnotetext{
${ }^{18}$ Consumption in figure 9 is the weighted sum of the active and inactive household members' consumption.
} 
Figure 9: Tax policies and allocations
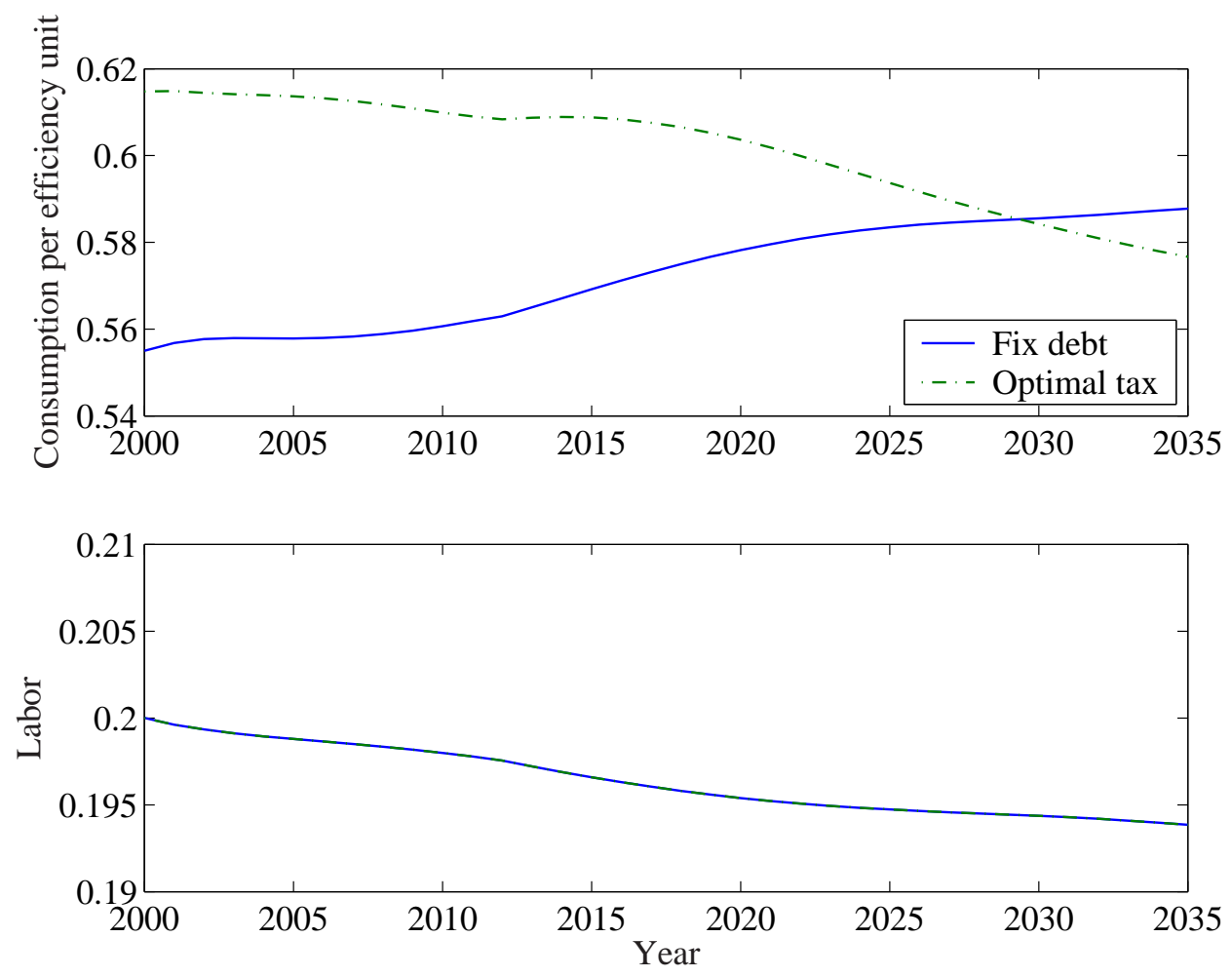

pensate the government under a suboptimal tax schedule to neutralize the welfare effect. To be more precise, let us consider the following two policy packages.

First, we have the fixed debt to GDP policy. The second package is the optimal taxation policy described above with the supplement of an additional initial debt imposed on the government. For the two packages to give the same discounted utility, the initial additional debt under the optimal policy would have to be 0.12 times GDP. This is a present value measure of what the household would indirectly (i.e. through future tax payments) be willing to give up to get the optimal policy. Important factors for determining the size of this effect are the changing dependency ratio through the epidemic, the household's intertemporal elasticity of substitution $(1 / \sigma)$ and labor supply elasticity.

If I were to lower $\sigma$ from 2 to 1.5 , then the corresponding additional debt burden 
Figure 10: Debt under different tax policies

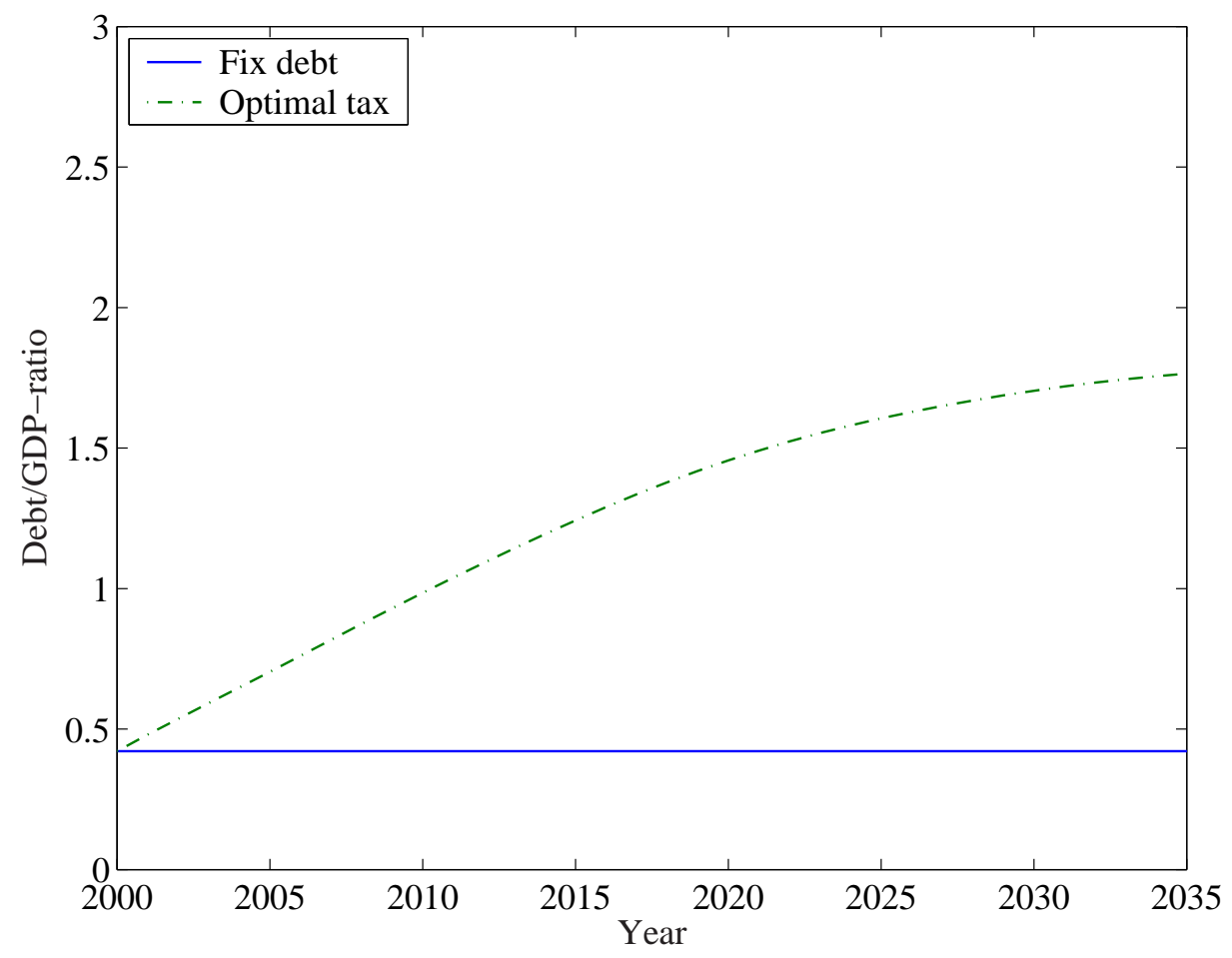

would be 0.08 times GDP. ${ }^{19}$ As would be expected, the welfare effect of choosing an optimal policy is no longer as high. If I were instead to increase $\gamma$ from 0.7 to 1 , the additional debt burden would have to be 0.11 times GDP for the household to be indifferent between the two policies. ${ }^{20}$ However, the general result still remains - the choice of tax policy is indeed important. The conclusion is that in an economy which goes through demographic changes and where the households are credit constrained, there will be significant welfare effects if the government cannot postpone some of the cost for the epidemic and take advantage of the long-run falling dependency ratios.

Let us return to the baseline value of $\sigma=2$ and $\gamma=0.7$ and assume that the government chooses to implement a full ARV intervention program. In this case,

\footnotetext{
${ }^{19}$ With an increase in $\sigma$ to 2.5 , the additional debt would have to be 0.15 times GDP.

${ }^{20}$ The baseline parameterization of $\gamma=0.7$ results in a Frisch labor supply elasticity of approximately 0.48 and with $\gamma=1$ the same elasticity is 0.61 .
} 
the corresponding additional debt burden under optimal policy would have to be 0.08 for welfare to be the same as under a fixed debt rate policy. That is, under full ARV intervention, the choice of tax regime will have less impact on household welfare than under the baseline intervention.

Critical for these results is the assumption made about the household credit constraint. In the baseline case, household revenues must equal household expenditures within each period. Now, I loosen this assumption and instead impose a lifetime budget constraint. Within each period, revenues and expenditures no longer need to match.

Ceteris paribus the household will supply less labor and consume more under the peak of the epidemic without than with the credit constraint. Hence, it will build up a debt that future cohorts of the household will service. The assumption made about the household's credit constraint is, indeed, very important for the result. Without any household credit constraint, the argument for government intervention (with possible support of international donors) is not as strong. As would be expected, the choice of taxation policy will not be as critical to household welfare when it is free to borrow. The household would now be prepared to accept only 0.002 times GDP in additional initial government debt for an optimal taxation schedule, as compared to a fixed debt rate policy. ${ }^{21}$ Recall from the previous section that when the household cannot borrow, it is willing to accept 0.12 times GDP in initial government debt to have the optimal tax schedule.

If the government or the household is free to borrow and optimize under an intertemporal budget constraint, this will lead to an increase the net foreign debt of the countries. In figure 11, we see the development of aggregate domestic assets in the two cases. $^{22}$ Although the development of domestic assets will be similar in

\footnotetext{
${ }^{21}$ This figure is derived in the same way as when different tax policies were compared in section 4.3. That is, I subject the household to two different policy packages: package one is a fixed debt policy and package two is the optimal (Ramsey) tax policy plus an initial additional government debt. The size of the debt is determined so that the household will be indifferent between the two policy packages. The additional debt is then a fiscal measure of the household's valuation of the optimal policy.

${ }^{22}$ The initial aggregated domestic assets will be negative and equal to the government's assets
} 
the two cases, the final steady state domestic debt is less in the model with a credit constrained household and an optimal tax policy.

As already discussed, it is reasonable to assume that the household is credit constrained. However, also the government faces constraints and it may have a good reason to pursue a tight fiscal discipline. It can be very hard to arrive at, and maintain, fiscal discipline. Once the government starts to allow itself to run budget deficits and finance expenditures, it might be hard to return to a balanced budget. With a large debt, the government also exposes itself to larger risk. The margins are thinner in case of unforeseen economic shocks and, at some point, the credit rating of the country will fall and the cost of borrowing will increase - neither of which is included in the this model. An alternative would be for the donors to provided general budget support for current expenditures over the peak of the epidemic. Then, the government can maintain service and grant levels without having to increase taxes and/or government debt. Let us say that the donors would like to contribute an amount equal to what the households would be willing to sacrifice to obtain a better intertemporal allocation. The donors should then contribute budget support equal to approximately $10 \%^{23}$ of GDP in the year 2000, spread over the peak of the epidemic.

(recall that the government starts with a debt, $D_{0}=0.42$, and that the household begins with zero assets, $\left.a_{0}=0\right)$.

${ }^{23}$ Between 0.08 and 0.12 according to the above analysis, depending on to what degree the ARV intervention is rolled out and the resulting impact on the dependency ratio. 
Figure 11: Aggregate domestic assets

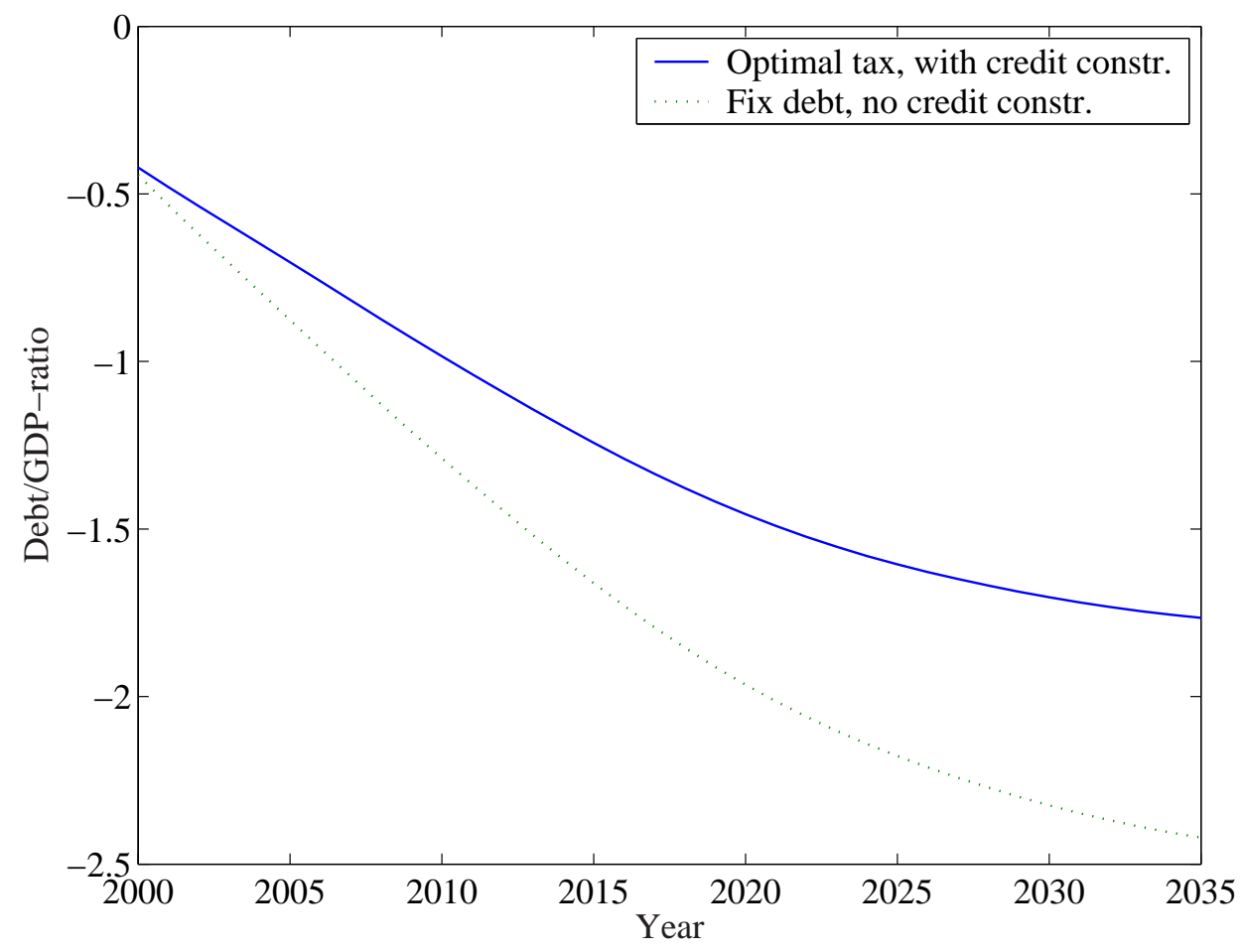

\subsection{Open vs. closed economy}

The assumption of a small open economy is critical for the above analysis. The implication is that factor prices are determined by the world market and will not change, regardless of what happens to productivity, demography, etc. There is no direct link between domestic investment and savings.

To close the economy, I will have to make an alteration to the model, since it contains no domestic capital owner. By definition, all capital must be domestically owned in a closed economy. Therefore, I introduce a second household in the model consisting of a capital owner. The capital owner maximizes

$$
\sum_{t=0}^{\infty} \beta^{t} U\left(v_{t} \hat{c}_{t}^{k}\right)
$$


subject to

$$
a_{k, t+1}=a_{k, t}\left(1+r_{t}\right)+v_{t} \hat{c}_{t}^{k}
$$

where $\hat{c}^{k}$ is the capitalist's consumption per efficiency unit and $a_{k}$ is her assets. In the steady state, $\hat{c}^{k}$ is constant. ${ }^{24}$ Furthermore, the domestic capital market must clear in each period

$$
a_{t}+a_{k, t}-D_{t}=k_{t} .
$$

That is, the households' and the government's aggregated savings must equal capital. The initial asset of the capital owner is equal to the net foreign asset in the first period in the baseline case above; else, the assumptions are the same as in the baseline case. $^{25}$

There will be no dramatic difference in allocations in an open as compared to a closed economy. During transition, capital and consumption will be somewhat less in the closed economy (see figure 12). ${ }^{26}$ The interest rate will be higher and wages lower in the closed economy (see figure 13).

Most closed economy papers predict that the capital/labor ratio increases as AIDS takes its toll. This will reduce the return to capital and increase the return to labor. However, this does not happen in the open economy, since capital will go abroad, thus adjusting the capital labor balance when the workforce is reduced. (Haacker, 2002)

Let us compare a closed economy with baseline intervention with a closed economy with full ARV intervention, to see whether the result will be the expected, that is a higher capital labor ratio in the baseline scenario. The baseline intervention (i.e. a situation with high AIDS rates) will indeed give a higher capital-labor ratio as shown by figure 14. The ratio of the interest rate to that of the wage becomes a

\footnotetext{
${ }^{24}$ The functional form of the utility function is the same as for the inactive part of the working household, that is $U\left(v_{t} \hat{c}_{t}^{k}\right)=\frac{\left(v_{t} \hat{c}_{t}^{k}\right)^{1-\sigma}}{1-\sigma}$.

${ }^{25}$ That is, the working household is credit constrained and the government pursues a fixed debt policy and the baseline AIDS intervention policy.

${ }^{26}$ Consumption is the weighted sum of consumption of the active and inactive. The curves show consumption and capital per efficiency unit.
} 
mirror image of the capital-labor ratio. With a relatively high capital-labor ratio, the interest rate will be relatively low. In the open economy, the capital-labor ratio, as well as relative factor income, will be constant, regardless of AIDS prevalence rates. $^{27} 28$

Figure 12: Allocations
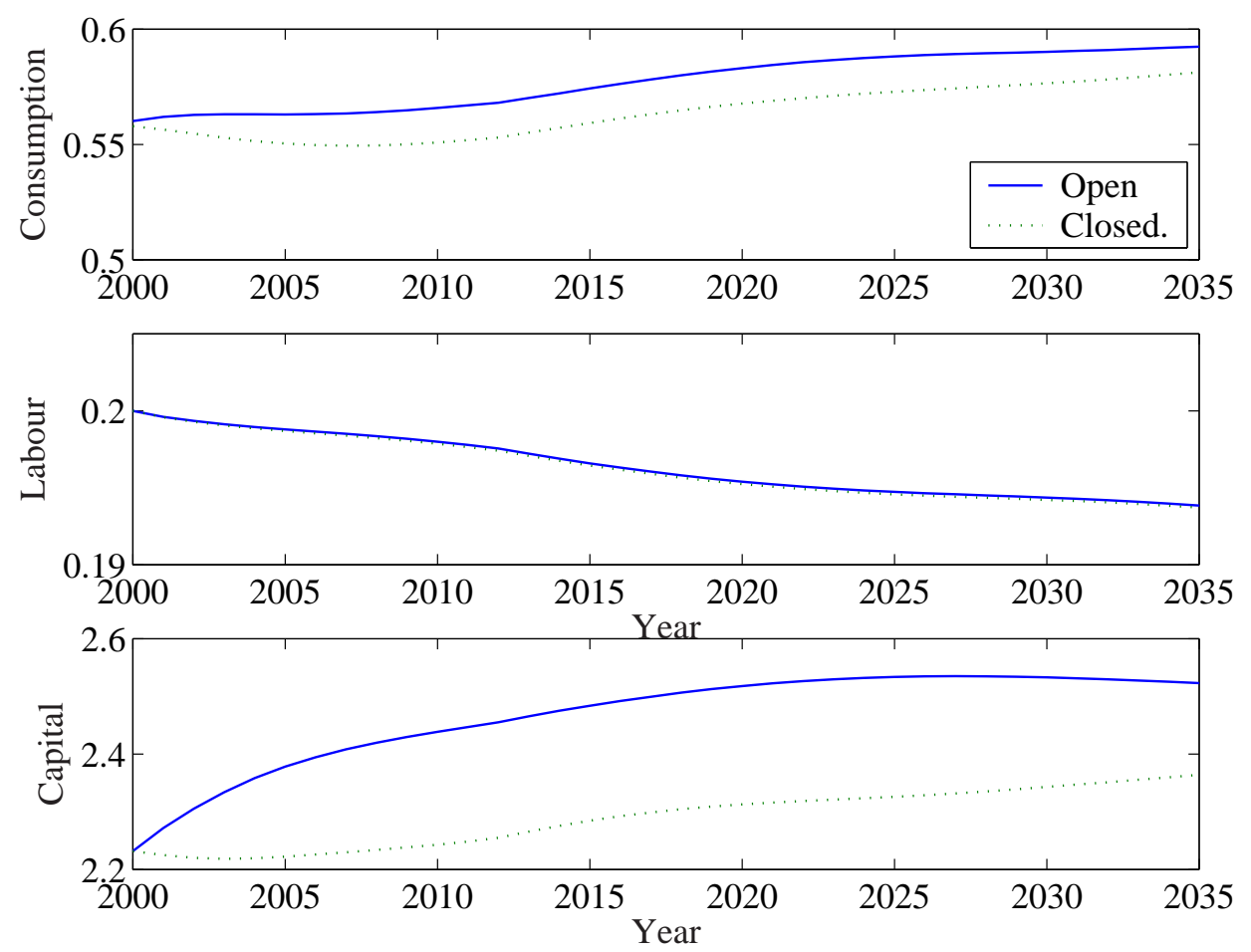

\footnotetext{
${ }^{27}$ The capital-labor labor ratio in figure 14 is defined as $k_{t} / H_{t}$. Note that, from equation 2.12 we have that the capital-labor ratio in the open economy is equal to $\phi$.

${ }^{28}$ In the final steady state, the capital-labor ratio will be the same in the closed economy as in the open, regardless of which dependency ratio we have. This is at odds with Haacker (2002) and others. Why is that? The household's saving decision is endogenous in my model. The rate at which households discount future utility will determine the steady state interest rate. With a given household discount rate, there can only be one given steady state interest rate. The reason why we find other results, in for example Haacker, is that the saving decision is not endogenized in a general equilibrium framework.
} 
Figure 13: Tax rate and prices
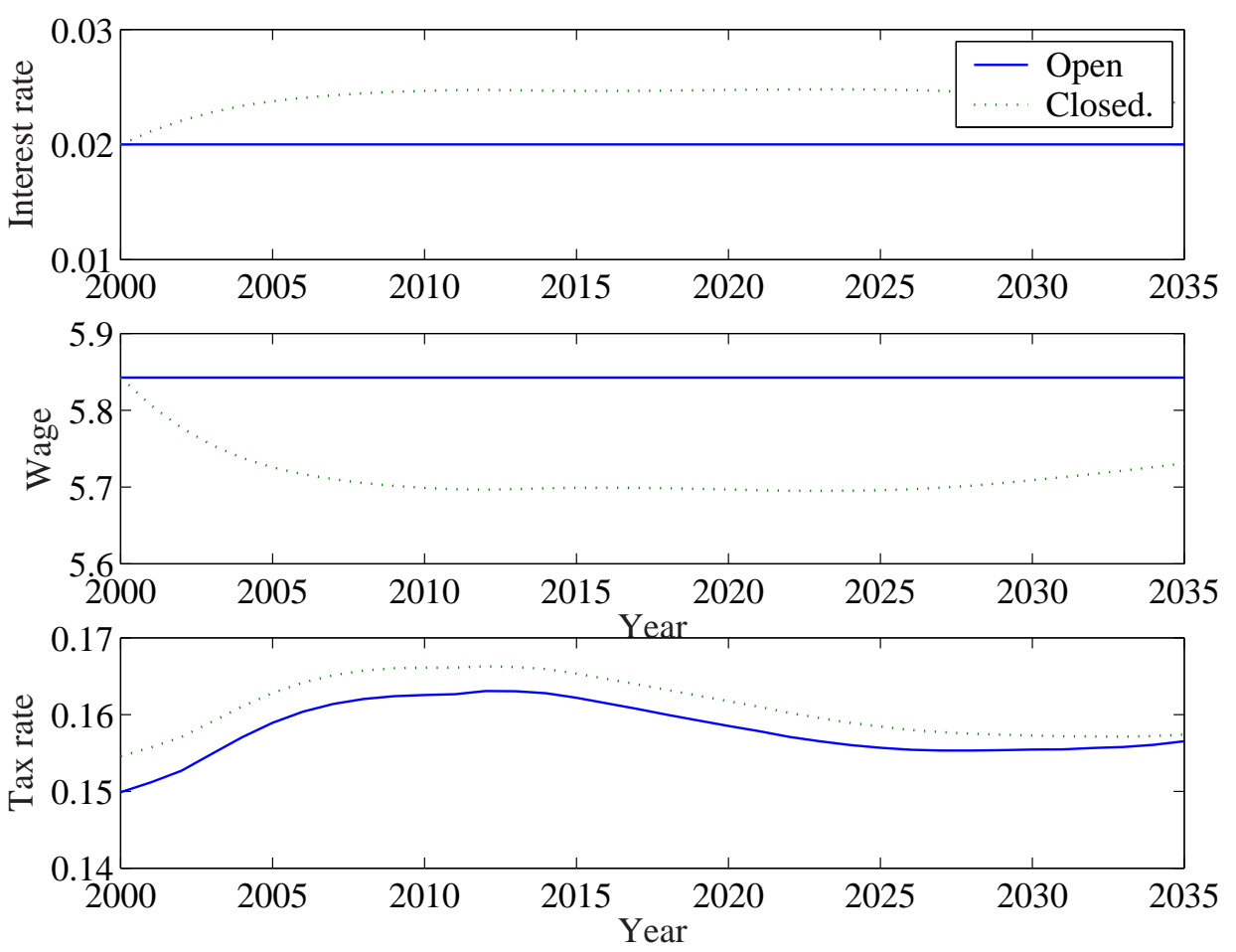
Figure 14: Comparing baseline intervention with full intervention in a closed economy
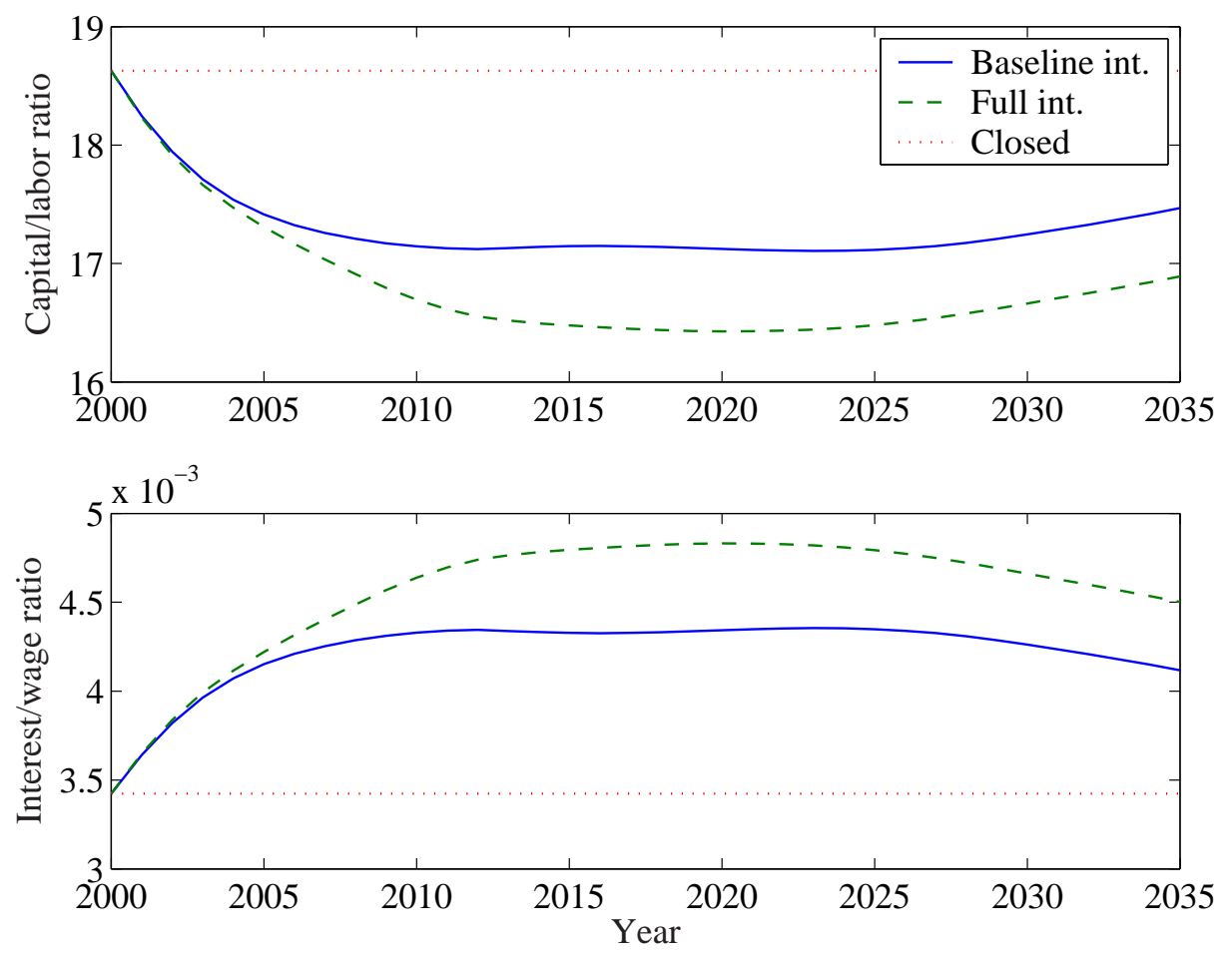


\section{Concluding remarks}

The main contributions of this paper are to point at the fiscal benefit of a full epidemiological intervention and the welfare impact of different tax regimes over the period 2000 to 2030 in South Africa. If households are assumed to be credit constrained, intertemporal financing of government expenditures is important. The households would be willing to accept an additional R 104 billion (or 12\% of GDP) in government debt, if the government were to choose a welfare optimizing tax schedule as compared to applying a fixed debt to GDP policy in the baseline scenario. If the government chooses to implement a full ARV intervention program, the choice of tax regime is somewhat less important. The tax regime will not be important for the household if it can freely borrow and lend to smooth its consumption.

The fiscal value of a full intervention program over the period 2000-2030, as compared to the baseline intervention, would be equivalent to $10.0 \%$ of GDP in the year 2000 or R 89 billion. This is when I assume that the government only covers $26 \%$ of the committed treatment cost of opportunistic diseases. I also showed that for an ARV intervention, the demographic impact on the fiscal flows of taxes, transfers and government consumption is more important than the direct health care cost savings.

How does the positive fiscal effect of an ARV intervention compare to the cost of the intervention - does it have any significance? The answer is yes. In Geffen and Nattrass (2004), the average annual cost of ARV treatment is estimated to be R 3.0 billion for the period 2002 to 2015 under the full intervention scenario of the ASSA model. That makes an annual cost per person treated of R 4838 in year 2000 prices. If we take this estimate and multiply by the number of people receiving ARV between 2000 and 2030, assuming that the cost would be the same over the whole period, we will get a total present value cost of $\mathrm{R} 94$ billion. ${ }^{29}$ That is, the positive

\footnotetext{
${ }^{29}$ The number of persons receiving ARV medicines each year is given by figure 15 . The total number of person-years of ARV treatments between 2000 and 2030 is 29 million. These numbers are based on the demographic model developed by the Actuarial Society of South Africa.
} 
Figure 15: People receiving ARV medicines

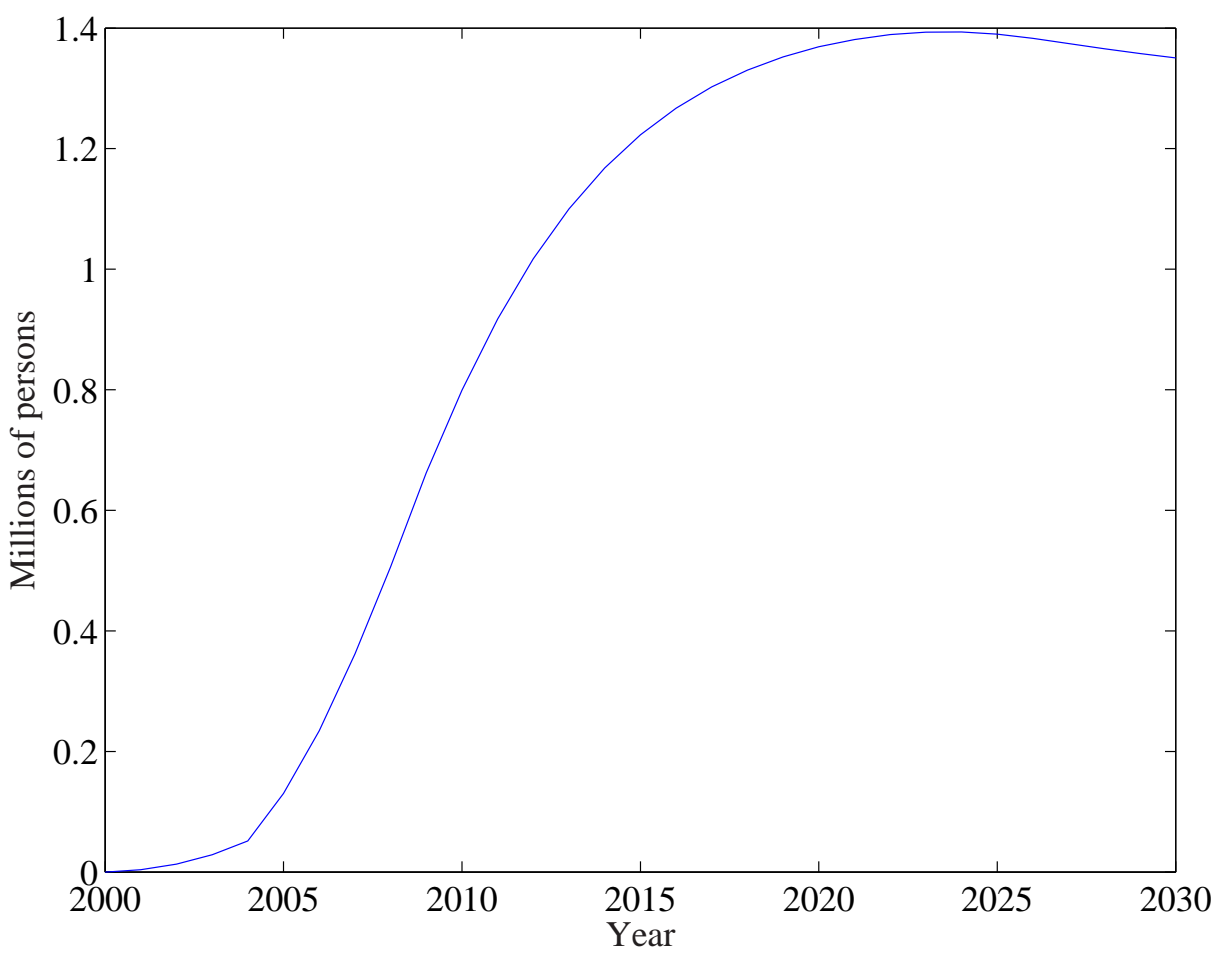

fiscal effect of a full ARV intervention would to a large extent pay for the cost of such an intervention. ${ }^{30}$

Here, I have only compared the positive fiscal impact with the cost of an ARV intervention. A full intervention against HIV/AIDS includes more elements such as mother to child transmission prevention, treatment of sexually transmitted diseases, information campaigns and counseling. The cost for these additional interventions is, however, minor as compared to the cost of antiretroviral drugs. How interventions are financed in the end will, of course, be of significance to the SA economy. Large external funds into one activity, such as an HIV/AIDS intervention, may cause Dutch

\footnotetext{
${ }^{30}$ The extent to which an ARV intervention is self-financing is sensitive to the assumption about productivity growth in the model. With a larger productivity growth or a further drop in prices for ARV drugs, the intervention could be more than self-financing. Note that the estimates in this paper are based on a rather modest assumption of a $0.5 \%$ annual real growth rate. Furthermore, if the government were to cover a larger share of the care cost for opportunistic diseases of HIV+ patients than the $26 \%$ assumed in this paper, the fiscal benefit of an ARV would, of course, increase.
} 
disease effects with an impact on other sectors of the economy. If the interventions are financed by current or future taxing of labor, capital or profits or by reducing investment in essential infrastructure, education etc., this will have an impact on productivity. Including a negative effect on factor productivity of the financing of intervention will lead to a less positive fiscal impact of interventions than that calculated in this paper. There are also constraints to intertemporally reallocating the financing of public expenditures by loans. Higher government debt will make the government more vulnerable to unforeseen economic shocks and will probably make borrowing more expensive. These are all additional aspects that policy makers will have to consider, but which are not explicitly dealt with in this paper. 


\section{References}

Arndt, C. and D. Lewis, J., 2000, December. The macro implications of hiv/aids in south africa: a preliminary assessment. The South African Journal of Economics $68(5)$.

ASSA, 2005, November. ASSA2003 AIDS and demographic models - user guide. Can be downloaded from ASSA's web-site: www.assa.org.za.

Atkinson, A. B. and J. E. Stiglitz, 1980. Lectures an public economics. McGRAWHILL book company (UK) ltd.

Bell, C., S. Devarajan, and H. Gersbach, 2003, June. The long-run economic costs of aids: theory and an applicaiton to south africa. World Bank, Policy Research Working Paper No. 3152, forthcoming, 2006, World Bank Economic Review.

BER, 2001. The macro-economic impact of hiv/aids in south africa. Economic research note No 10, Bureau of Economic Research, University of Stellenbosch.

BIDPA, 2000, 31 August. Impact of hiv/aids on poverty and income inequality in botswana. Botswana Insitute for Development Policy Analysis.

Domej, D. and M. Floden, 2004, August. The labor-supply elasticity and borrowing constraints: Why estimates are biased. Downloaded from http://web.hhs.se/personal/floden/, Forthcoming in Review of Economic Dynamics.

Flodén, M., 2003. Public saving and policy coordination in aging economies. The Scandinavian Journal of Economics 105(3).

Geffen, N. and N. Nattrass, 2004, December. The impact of reduced drug prices on the cost-effectiveness of haart in south africa. Research Summary, University of Cape Town. 
Geffen, N., N. Nattrass, and C. Raubenheimer, 2003, January. The cost of hiv prevention and treatment interventions in south africa. CSSR Working Paper No. 28, University of Cape Town.

Haacker, M., 2002, February. The economic consequences of hiv/aids in souther africa. IMF working paper, wp/02/38.

ING Barings Southern Africa ltd., 2000, April. Economic impact of aids in south africa - a dark cloud at the horizon.

Nattrass, N., 2004. The Moral Economy of AIDS in South Africa (1 ed.). Cambridge Africa Collection. Cambridge University Press.

SA Reserve Bank, 2002, June. Quartarly bulletin.

Statistics South Africa, 2004. Census 2001: Primary tables South Africa, cencus 96 and 2001 compared. Report No. 03-02-04 (2001). Statistics South Africa.

UNAIDS, 2006. 2006 report on the global aids epidemic.

UNDP, 2001. Human Development Report. Oxford University Press.

van der Berg, S., 2001a, Summer. Redistribution through the budget: public expenditure incidence in south africa, 1993-1997. Social Dynamics 27(1), 140-164.

van der Berg, S., 2001b, October. Resource shifts in south african schools after the political transition. Development southern Africa 18(4), 405-421.

Young, A., 2005, May. The gift of the dying: the tragedy of aids and the welfare of future african generations. Quarterly Journal of Economics 120(2), 423-466. 


\section{A More on parameterization}

\section{A.1 The demographic profiles}

The demographic profiles of this paper are based on the demographic model developed by the Actuarial Society of South Africa (ASSA). The population in their model is disaggregated on basis of sex, age, population group and risk group with different assumptions on fertility and mortality for infected and non-infected persons. The risk groups range from a group of people at no risk at all of becoming infected to people with a sexual activity similar to that of commercial sex workers. Within each risk group, the modelers have made assumptions about sexual activity, contacts with individuals from different risk groups, condom use and probabilities of becoming infected when involved in unprotected sex. There are also specific assumptions about mother to child transmission of HIV.

A mortality rate of $30 \%$ per annum is assumed for children born with the virus and a median time to death of six years for those who contract the disease via mothers' milk. Otherwise, the model assumes a median time to death of 11 years for those under 25 and 10 years for those that are 25 years or older when infected. The model has been calibrated to give as good a fit as possible with existing information on population and prevalence rates. For more details on the model, see the user guide "ASSA AIDS and demographic models" (ASSA, 2005).

In the model, as people get ARV treatment, it is assumed that this will lead to a $75 \%$ reduction in morbidity rate among both adults and children. That is, ARV does not mean that an HIV positive person will not get AIDS, it just means that this is likely to happen later rather than earlier.

From the demographic model, we can obtain different data. For example, figure 16 plots the dependency ratio and the share of AIDS sick in the population. In the top graph, I have plotted the dependency ratio both for a no-AIDS scenario and for an AIDS-inclusive scenario (with the baseline epidemiological intervention). 
Although, the AIDS epidemic, in the model, has been going on since the year 1985, it is only after the year 2000 that it starts to have a significant impact on the dependency ratio.

From the ASSA model, I first extracted a population parameter $n_{t, i, j}$ which is population in year $t=2000,2001, .$. , at age $i=0,1, . . .90$ and with HIV /AIDS status $j=1$ (HIV-negative), 2 (HIV-positive first and second stage), 3 (HIV-positive, third stage), 4 (AIDS sick without ARV) 5 (people on ARV). The parameter $n_{t}$ used in the model is

$$
n_{t}=\sum_{i=0}^{90} \sum_{j=1}^{5} n_{t, i, j} .
$$

Figure 16: AIDS sick and the dependency ratio
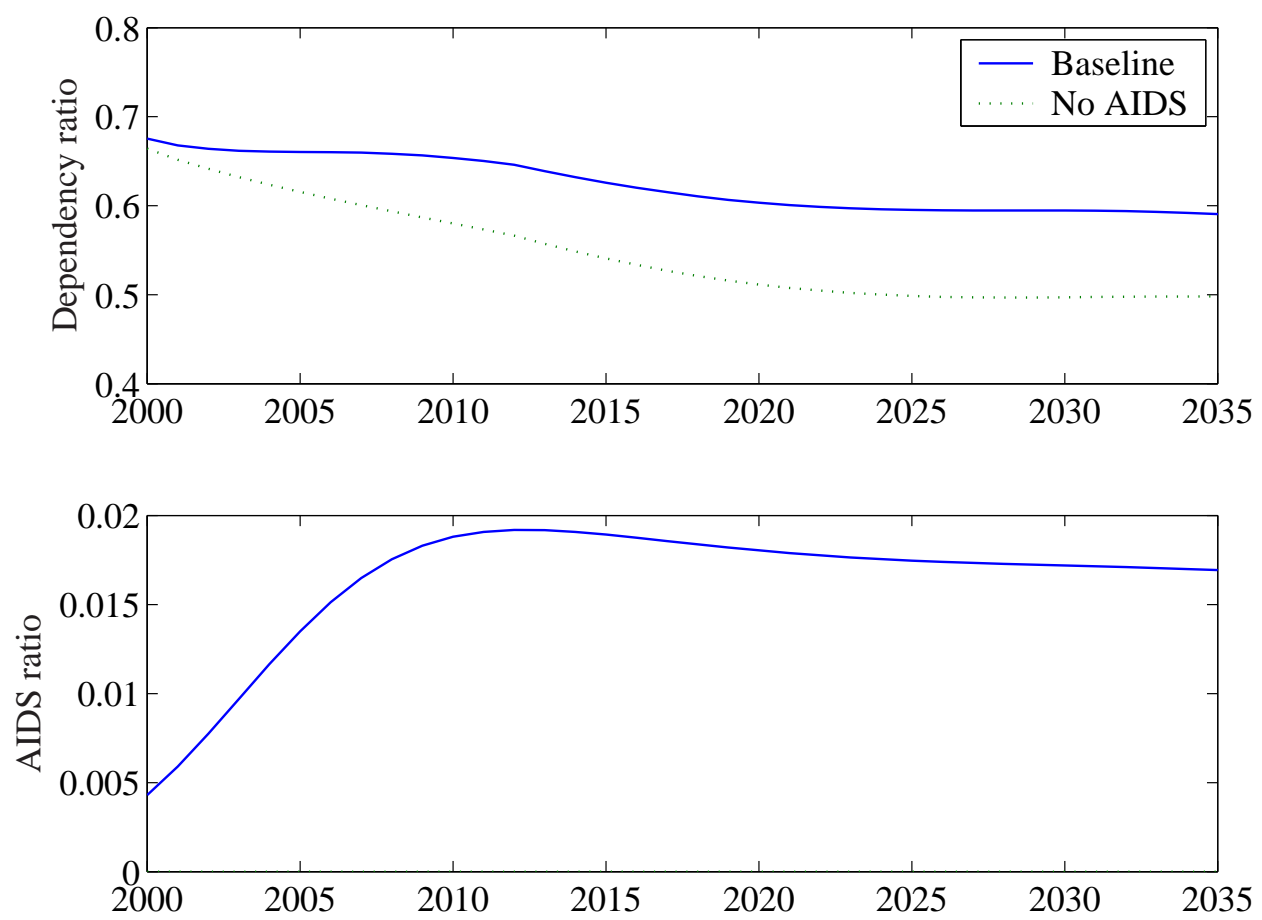


\section{A.2 Active population and productivity profile}

To calculate the productivity profile for the household, I use Statistics South Africa's Income and Expenditure Survey (IES) for the year 2000. I take the mean income and divide it by the mean of the time at work. I use three-year moving averages to smoothen this figure. The income variable is made up of the sum of the variables P2401Q0101, P2401Q0102, P2401Q0103, P2401Q0104 and P2401Q02. The working time variable is made up of "worked", where I changed all values "worked" $=2$ to "worked" $=0$, and then took the mean. This mean is then the share of respondents that said they had been doing any work during the last seven days. This is a very imprecise measure of the extent to which people work. Both household income and employment are believed to be underestimated in the 2000 census Statistics South Africa (2004). Mean income is shown in the upper plot of figure 17. Labor supply is in the next plot and the resulting productivity profile, $V_{i}$, for $i=16,17, \ldots \ldots 65$ is in the bottom graph.

To get the measure for productivity used in the model, $v_{t}$, I take the weighted sum for the productivity of each active age group. The weights are each age group's share of the total active population of the household; that is,

$$
v_{t}=\sum_{i=16}^{65} V_{i} \frac{\sum_{j=1}^{3} n_{t, i, j}+0.75 n_{t, i, 5}+0.55\left(n_{t, i, 4}+0.25 n_{t, i, 5}\right)}{\sum_{i=16}^{65}\left[\sum_{j=1}^{3} n_{t, i, j}+0.75 n_{t, i, 5}+0.55\left(n_{t, i, 4}+0.25 n_{t, i, 5}\right)\right]} .
$$

Productivity profiles are assumed to be constant over time, but the productivity measure will still change between periods because the relative share of different active age-groups changes.

The share of active, $\alpha$, in the household is the share of people aged 16-65 (less $45 \%$ of the AIDS sick) to that of the total population. Because of the changing population profiles, the shares of active will also change over time, such that

$$
\alpha_{t}=\frac{\sum_{i=16}^{65}\left[\sum_{j=1}^{3} n_{t, i, j}+0.75 n_{t, i, 5}+0.55\left(n_{t, i, 4}+0.25 n_{t, i, 5}\right)\right]}{n_{t}} .
$$


Figure 17: Productivity
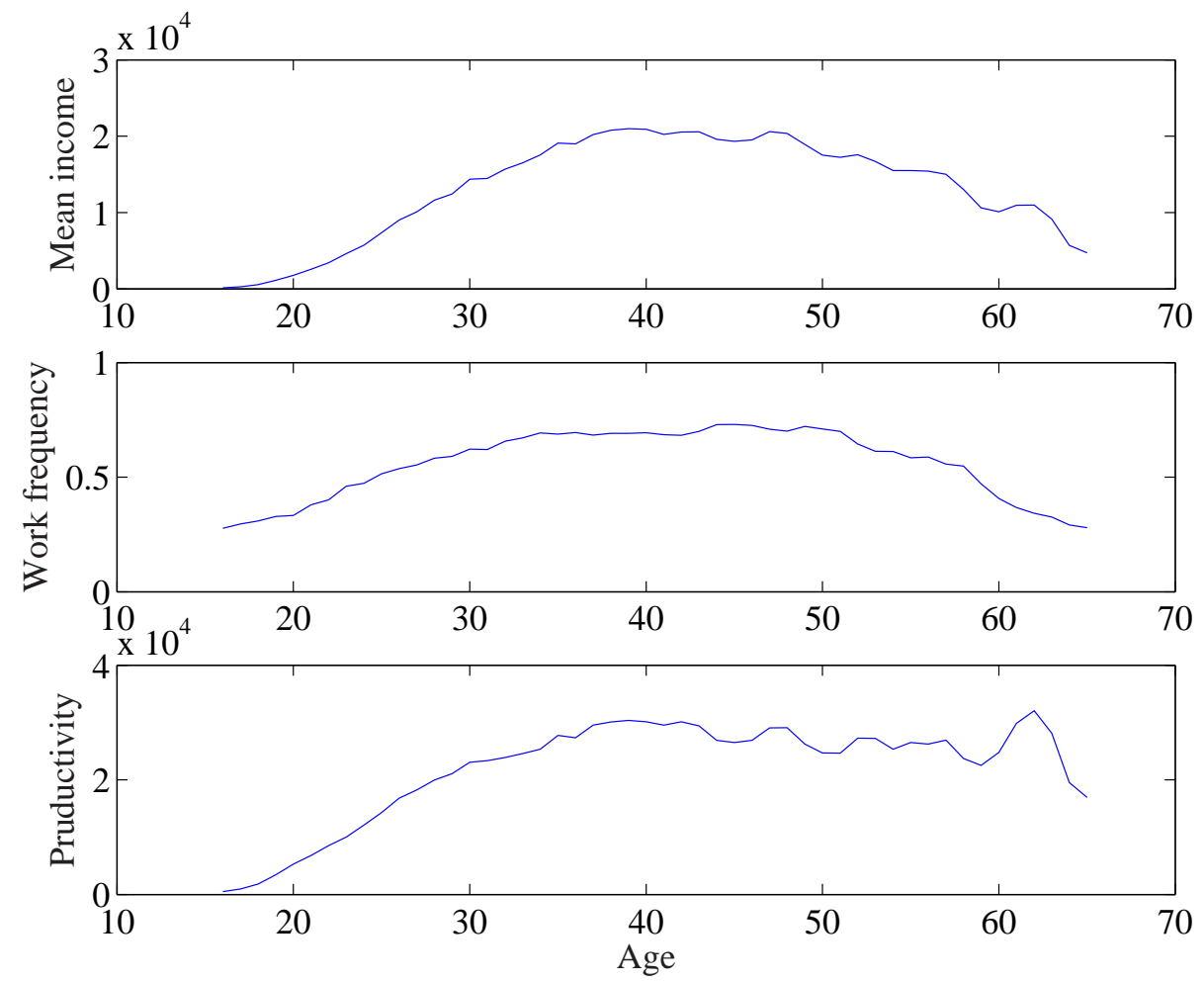

Notes: Based on the IES 2000.

\section{A.3 Social transfer profile}

The parameter for transfers to the two households was calculated in the following way. From the IES 2000, I added up the variables for Social pensions or allowances (P2401Q070301), Disability grants (P2401Q070302), Family and other allowances (P2401Q070303) and the workmen's compensation (P2401Q0704). For these summed social transfers, I take the mean for each age group between 0 to 90 years of age and then multiply this profile on transfers to the household with the ASSA2000 population profile for the year 2000. If all figures gave an accurate picture of the social transfers in the year 2000, they would match macro data on transfers to household in that same year.

However, the macro data SA Reserve Bank (2002) gives a figure that is $49 \%$ higher than what is obtained from combining IES data with output from ASSA2000. 
There might be flaws in the macro data, the micro data of the IES and data from the population model. It is generally considered that there are problems with underreporting on benefits in the IES 2000, but it is outside the scope of this study to proceed further into these issues. What I do is that I accept the aggregated figure on transfers and then adjust the level of the transfer profile obtained from the IES so that the micro data matches the macro data when applying the demographic profile from ASSA. The profile for social transfers, $S_{i}$, obtained from IES, is plotted in figure 18. The variable $s_{t}$ used in the model is

$$
s_{t}=\sum_{i=1}^{90} S_{i} \frac{\sum_{j=1}^{5} n_{t, i, j}}{n_{t}} .
$$

Figure 18: Social transfers

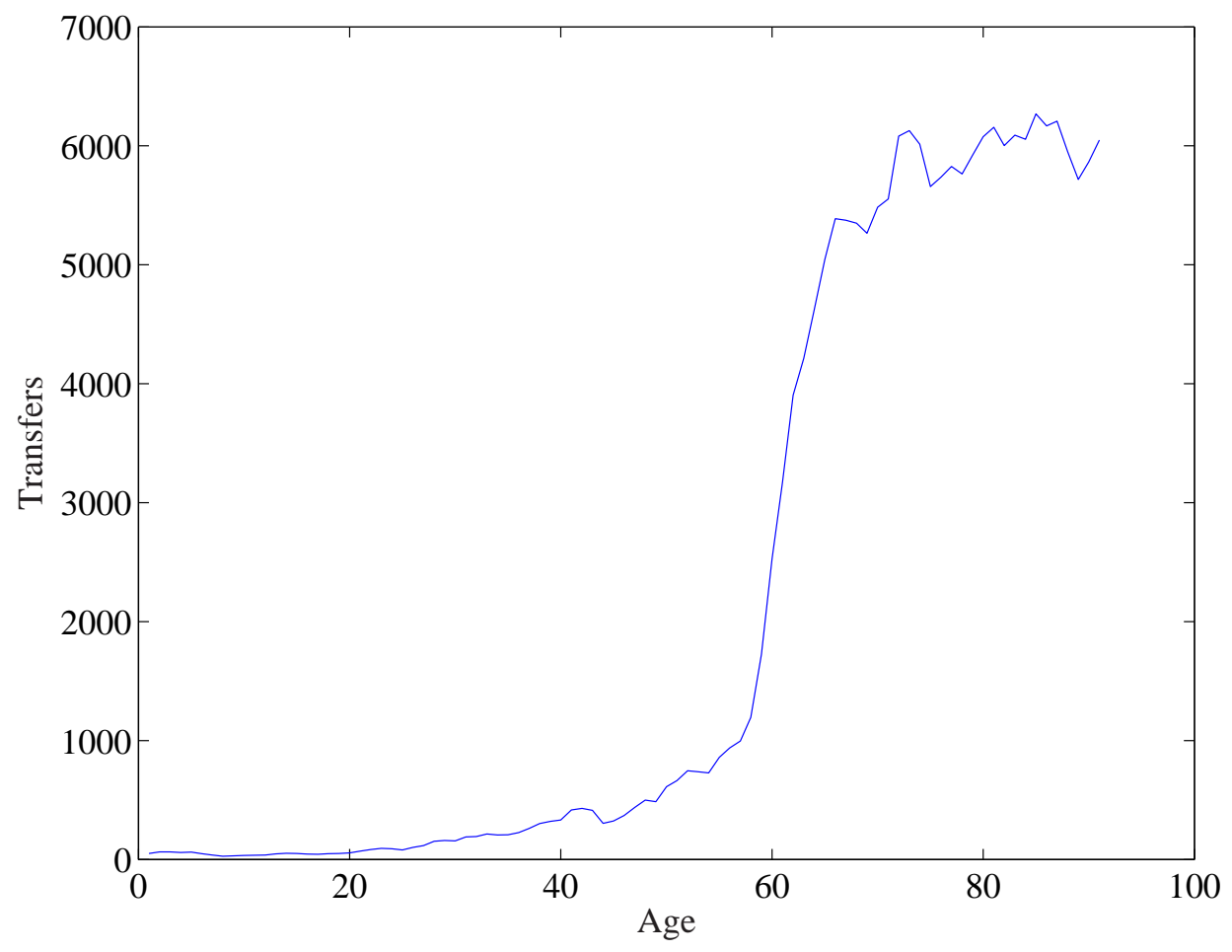

Notes: Based on the IES 2000. 


\section{A.4 Government consumption profile}

Educational expenditures have been distributed over ages 7-26. Apart from education, health expenditures are also to a large extent age dependent. Old and young people generally consume more health care services than (HIV-negative) people in their middle age. Unfortunately, I lack information to disaggregate health expenditures and other government consumption with respect to age. Hence, these expenditures have been split equally over the age categories. The resulting rough government consumption profile, $G_{i}$, in figure 19 was created on the basis of information from van der Berg (2001a,b), Statistics South Africa on spending on education and other government consumption and figures from the Human Development Report UNDP (2001) on enrollment rates.

Figure 19: Government consumption profiles

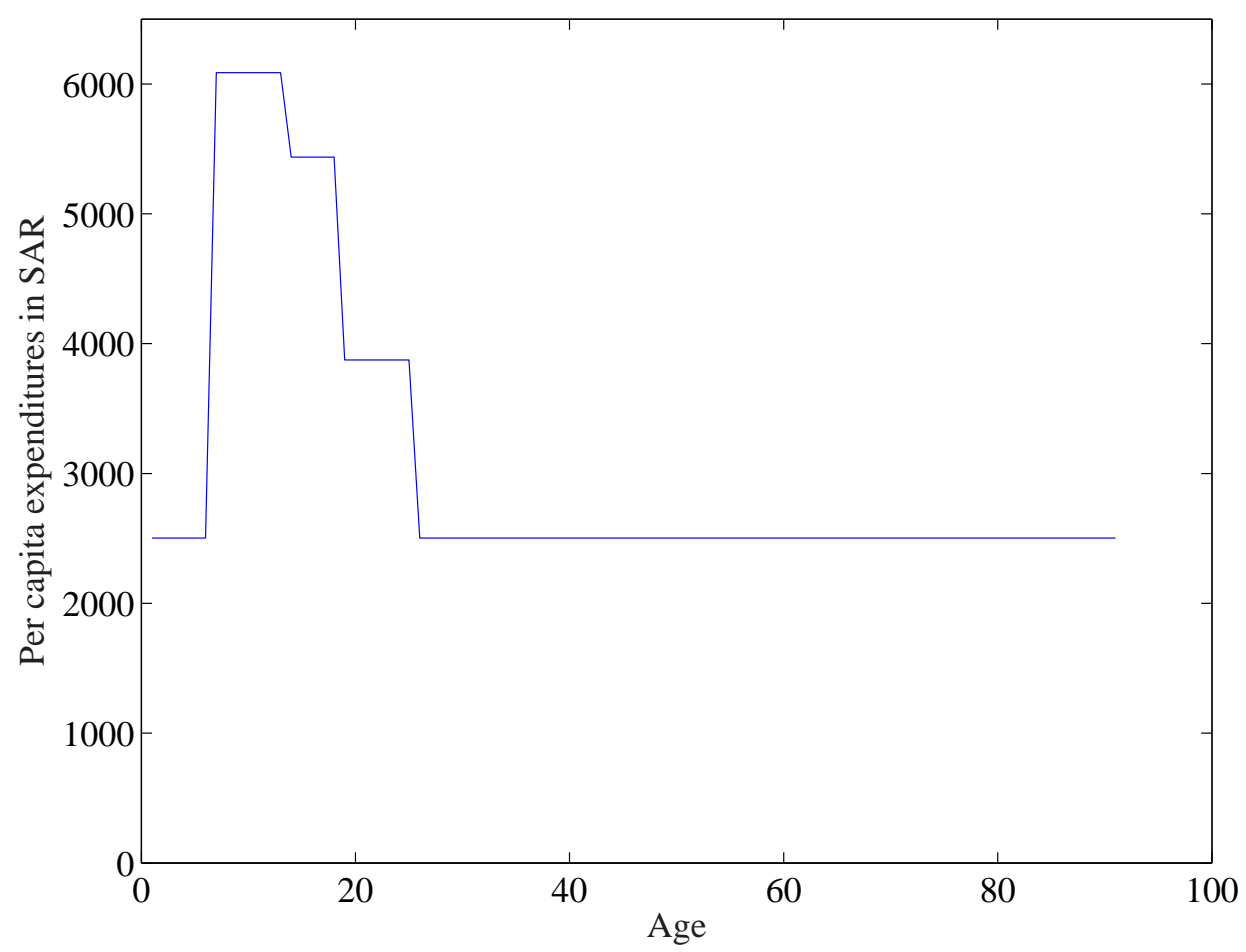

Notes: Based information from Statistics South Africa and other sources (see, the text).

This profile does not include the cost for treating HIV + people for opportunistic 
Table 2: Health care cost of AIDS

\begin{tabular}{ll}
\hline Stage & Cost per patient per year \\
\hline Adult stage one & R 1378 \\
Adult stage two & R 1378 \\
Adult stage three & R 6572 \\
Adult with AIDS & R 18020 \\
Adult on HAART who has become healthy again & R 1378 \\
Child pre-AIDS & R 1378 \\
Child with AIDS & R18 020 \\
\hline
\end{tabular}

Notes: Source, Geffen et al. (2003)

diseases. For each year, I add these expenditures using the cost estimates from Geffen et al. (2003). These are given in table 2.

There are two sources for the change of government expenditures over time. First, government expenditures will change because of the changing size and age profile of the general population. Second, the change in the number of HIV positive people in different stages will have an impact on government expenditures. Together, this gives us

$$
g_{t}=\frac{\sum_{i=1}^{90}\left[\omega\left(1378\left(n_{t, i, 2}+0.75 n_{t, i, 5}\right)+6572 n_{t, i, 3}+18020\left(n_{t, i, 4}+0.25 n_{t, i, 5}\right)\right)\right.}{G_{i} \sum_{j=1}^{5} n_{t, i, j}+},
$$

where $\omega$ is the coverage of health care cost for AIDS sick people (though, not including ARV treatment). In the baseline case, $\omega$ is equal to 0.26 but there are also some estimates in the paper with less rationing $(\omega=0.6)$. 